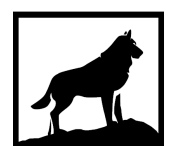

Michigan Technological

18 8 5 University
Michigan Technological University Digital Commons @ Michigan Tech

RECOMMENDATIONS FOR A COMMUNITY-LED MULTISTAKEHOLDER WATERSHED MANAGEMENT PLAN IN RURAL PANAMA

Tristan Odekirk

Michigan Technological University, todekirk@mtu.edu

Copyright 2021 Tristan Odekirk

Recommended Citation

Odekirk, Tristan, "RECOMMENDATIONS FOR A COMMUNITY-LED MULTI-STAKEHOLDER WATERSHED MANAGEMENT PLAN IN RURAL PANAMA", Open Access Master's Report, Michigan Technological University, 2021.

https://doi.org/10.37099/mtu.dc.etdr/1226 


\title{
RECOMMENDATIONS FOR A COMMUNITY-LED MULTI-STAKEHOLDER WATERSHED MANAGEMENT PLAN IN RURAL PANAMA
}

By

Tristan J. Odekirk

\begin{abstract}
A REPORT
Submitted in partial fulfillment of the requirements for the degree of

MASTER OF SCIENCE

In Civil Engineering
\end{abstract}

MICHIGAN TECHNOLOGICAL UNIVERSITY

2021

(C) 2021 Tristan J. Odekirk 
This report has been approved in partial fulfillment of the requirements for the Degree of MASTER OF SCIENCE in Civil Engineering.

Department of Civil, Environmental, and Geospatial Engineering

\author{
Report Advisor: Dr. David Watkins \\ Committee Member: Dr. Judith Perlinger \\ Committee Member: Dr. Kari Henquinet \\ Department Chair: Dr. Audra Morse
}




\section{Table of Contents}

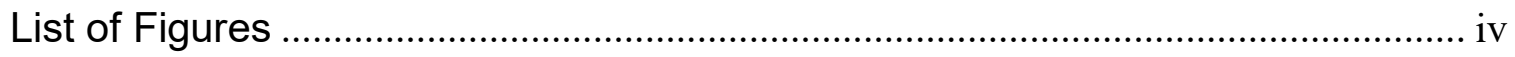

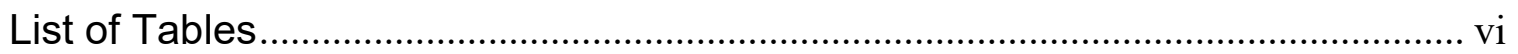

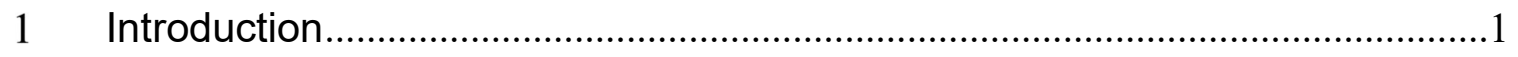

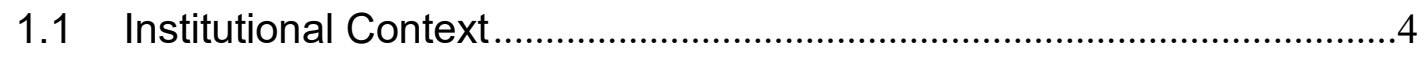

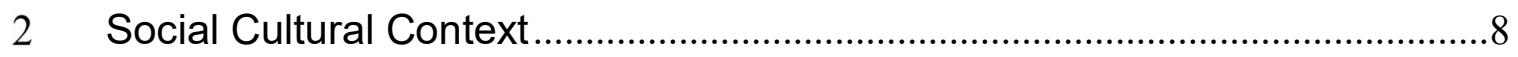

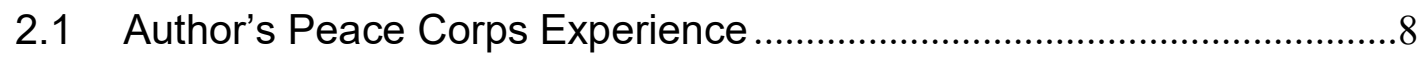

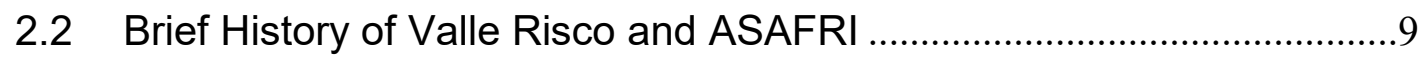

2.3 Social and Cultural Considerations..........................................................12

3 Technical and Logistical Considerations ……….............................................

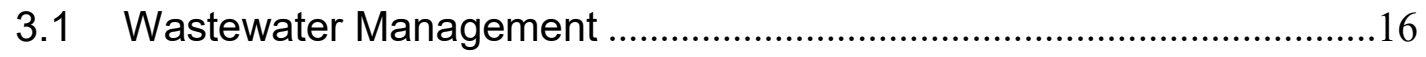

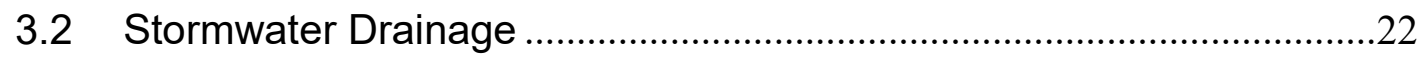

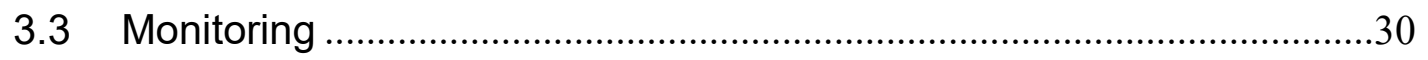

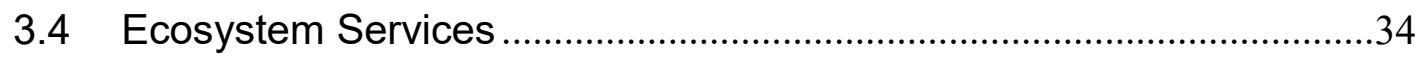

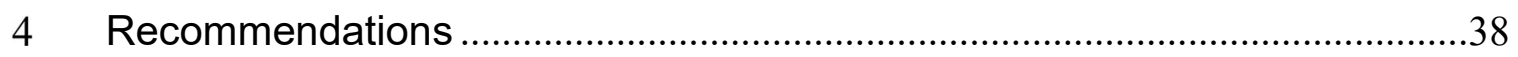

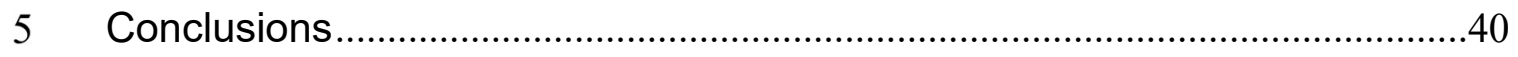

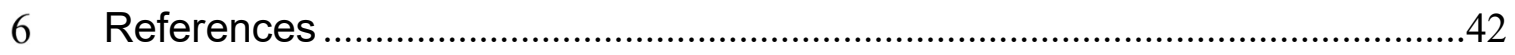

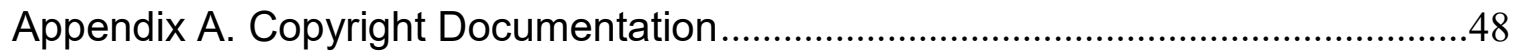

Appendix B. Household wastewater data ..........................................................50

Appendix C. Rainfall statistical analysis ………….............................................52 


\section{List of Figures}

Figure 1 Panama with Valle Risco shown. Image source: Google Maps. See Appendix A for full attribution and copyright licensing information....

Figure 2 the province of Bocas del Toro showing Valle Risco in relation to other cities (left) and its location in the Rio Changuinola watershed (right). Image source: Google Maps. See Appendix A for full attribution and copyright licensing information

Figure 3. Valle Risco. Image source: Google Maps. See Appendix A for full attribution and copyright licensing information. 3

Figure 4. Some of the surrounding communities which connect to Valle Risco. Image source: Google Maps. See Appendix A for full attribution and copyright licensing information.

Figure 5. View of the main area of Valle Risco. This is the entrance to the region via a bus stop, holds many shops, and is the location of many cultural events ranging from casual interactions to holiday parades and festivals. Photo by author.

Figure 6. Expansion of the elementary school to include a high school, gymnasium, laboratories, and a library. Photo by author. 11

Figure 7 Picture of Valle Risco development committee being formed. Photo by author. 15

Figure 8. Sketch of common seepage pit system. A flush toilet leads through 3"-4" PVC pipe into a pit lined with 8" cinder block. An overflow leads to either another pit or a drainage ditch/creek. Made by Author using SketchUp 2017.

Figure 9. Results of a survey of wastewater approaches in Valle Risco. This demonstrates the increasing prevalence of flush toilet systems referred to by locals as septic systems but includes seepage pits. Compost indicates composting toilet; $N O$ indicates no system installed. Data collection by author.

Figure 10. A white square of approximately $21,866 \mathrm{~m}^{2}$. This image is intended only to show the land necessary for for a facultative lagoon as compared to the size of Valle Risco. The location of the white square in the image is on a river bed, and a wastewater treatment system should not be placed here. Selecting a site for such a system would be an important discussion that should include many stakeholders. Image source: Google Maps. See Appendix A for full attribution and copyright licensing information. .20

Figure 11. Typical rainfall in Valle Risco. Such storms may last anywhere from 30 minutes to several days. Photo by author. 
Figure 12. A portion of the road into town washed out due to heavy rain. Photos by author.

Figure 13. Creeks (light blue) go through central Valle Risco and connect to Rio Risco (dark blue). Image source: Google Maps. See Appendix A for full attribution and copyright licensing information.

Figure 14. (Left) A ditch receiving runoff from the school. The edible plant taro grows in such ditches. Trash is visible. (Right) One of the main creeks which passes through town. Typical properties are seen in the riparian zone. Clear cutting causes increased runoff into the water. Also visible is a sleeping pig as well as some trash. Photos by author.

Figure 15. It is common practice to keep pigs tethered near creeks for easy access to water. Photo by author.

Figure 16. Solid waste accumulation and contamination in a main creek which runs behind houses and directly into Rio Risco. Photo by author. .25

Figure 17. Estimated watershed of which Valle Risco is the mouth. Boundary estimated using Google Earth, an ESRI digital elevation model, and my memory of the region (ESRI 2020). The white border indicates different land use type for use in rational method calculation. $10 \mathrm{~m}$ contour lines are shown in yellow and were obtained using the System for Automated Geoscientific Analyses in QGIS. Image source: Google Maps. See Appendix A for full attribution and copyright licensing information

Figure 18. IDF curves for rainstorms in Bocas del Toro. Data from (Smithsonian Tropical Research Institute 2021).

Figure 19. An upstream reach of Rio Risco is surrounded by much pasture land. Cows are an important source of revenue for the locals. An ES model may be useful in discussing appropriate uses of upstream land. (Photo by author)

Figure 20. Intensity-duration-frequency plot for Weibull plotting-position formula ........54

Figure 21. Intensity-duration-frequency plot for GEV distribution. ...............................57

Figure 22. IDF curves for adjusted GEV values. .59 


\section{List of Tables}

Table 1. Publications by the Panamanian government in the last decade describing efforts in environmental conservation.

Table 2. Technical documents referenced in the National Plan for Hydrological Resources. Each discusses various means of protecting surface waters from the effects of human use.

Table 3. Parameters to be measured according to the National Plan for the Integrated Management of Water Resources of the Republic of Panama 2010-2030

Table 4. Intensity-duration-frequency (IDF) table for Isla Colon using data from STRI (Smithsonian Tropical Research Institute 2021). Hourly GEV rainfall data between 2002 and 2021. Data collected by STRI and processed by author.

Table 5. Runoff coefficients from FDOT (January 2019) ……………………………....27

Table 6. Calculation using the NRCS curve number ....................................................27

Table 7. Parameters sampled by the Ministry of Health in David, Panama ......................31

Table 8. Maximum rainfall events for 2002-2020. Data from STRI 2021.........................52

Table 9. Sorted and ranked yearly maximum rainfall for use in the Weibull method. ......53

Table 10. GEV distribution values. ………………………………………………....56

Table 11. Adjustment factors for given sampling ratios. Values from Young and McEnroe

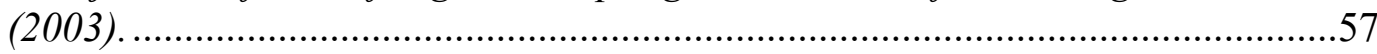

Table 12. Adjusted GEV values for maximum yearly rainfall intensity.............................58 


\section{Acknowledgements}

Finishing this report would not have been possible without the many people I am blessed to have in my life.

I thank my graduate committee David Watkins, Kari Henquinet, Judith Perlinger who were patient with me as I stumbled through understanding where I am going and were always available to lend a hand when needed or to talk and share when available.

To the community of Valle Risco who welcomed me into their town for two years. There is insufficient space for everyone who helped me, but a special thanks to my host family, to Maria Salima, Liberto Jimenez, Adelia Jimenez, Leticia Jimenez, Yolanda Jimenez, to my guides and friends Simon Guerra, Juan Carrera, Daniel Pineda, Jose Molino, Erluis Guerra, Ivan Guerra, Guadalupe Vega, and Eusebio Vega.

My work benefited greatly from the help, expertise, and teaching of my sector coordinators MC Moritz and Martin Cardales, the help and companion ship of my friends and fellow pcvs, students, and the friends who have helped me over time.

Last I thank my family, my parents David and Veronique, my brothers and sisters-in law Nicolas, Stephen, Jenn, and Kellie, and my niece Jasmine. 


\begin{abstract}
Valle Risco is a small, rapidly growing rural town in northwest Panama. As the town grows and develops those who live there have expressed concern at sustainably managing the surrounding watershed. This report consists of some considerations and suggestions for the community of Valle Risco as they build a strong town that plays a central role in the socioeconomic development of the region. This information is based on my experience working with the town as a Peace Corps Volunteer. Recommendations include solutions for wastewater management, storm water drainage, consistent water quality monitoring, and the use of ecosystem services as theme for multi-stakeholder decision-making processes. An important consideration in all decision-making processes is the recognition of indigenous sovereignty and the importance of community-based leadership.
\end{abstract}




\section{Introduction}

Valle Risco is a rural indigenous community beside Rio Risco, a major tributary of Rio Changuinola, in northwestern Panama (Figures 1-3). The town was founded by three Ngäbe families in the late 1950's and named for the abundance of wildlife that could sustain a community. As the town has grown to a population approximately 2500 people and continues to grow, and as development and infrastructure have kept up, the locals speak of a decline in the natural abundance for which the town was once named. While several community groups as well as Panamanian and non-government organizations have sought to help the community care for its natural heritage, few have implemented actual sustained monitoring of water quality and land use change effects on environmental health. This report seeks to aid this effort and provide some technical and logistical basis around which a watershed management plan may be developed and implemented.

Valle Risco is thought by many of its residents to be the largest entirely indigenous community in Panama outside of a Comarca (a provincial scale semi-autonomous indigenous area). As the population has increased, the constructed density and infrastructure have expanded causing a shift from subsistence agriculture towards a more market economy. Despite this, the town is currently still very reliant on a subsistence lifestyle bolstered by sales from cacao agroforestry from family plantations. With the formation of the Agroforestry Association of Valle Risco (ASAFRI) in the 1970s, most of the community members acknowledge the importance of environmental health in their sustained livelihood. Many reference the recent COVID pandemic as an example of how maintaining ties to the land provides resilience to the community as supply chains and access to income become strained. Even in regular times, the native flora and fauna provide a source of food and medicine for the greater area's 5000 residents. Being located in the Palo Seco Protected Forest (BPPS) continued preservation of biodiversity would help maintain livelihood and resiliency for the community as well as keeping intact important global ecosystems. Watershed health is connected with a number of other human and environmental health factors. Fecal contamination of surface waters is a major cause of illness and mortality, especially when more sanitary sources of drinking water are not consistently available. Pooling water also acts as a breeding ground for disease vectors such as mosquitoes and flies. Nutrient loading from human activities contributes to harmful effects on aquatic ecosystems that may adversely affect other biomes. Finally, increased impervious surface and channelization worsen any preexisting environmental threats and increases risk of flooding. At the time that I left Panama, Valle Risco was in the midst of planning major infrastructure development projects with the hopes of growing the population and firmly establishing the town as a major point of importance in the region. With an increasing population and access to technology comes the possibility of increased pressure of the environment. 


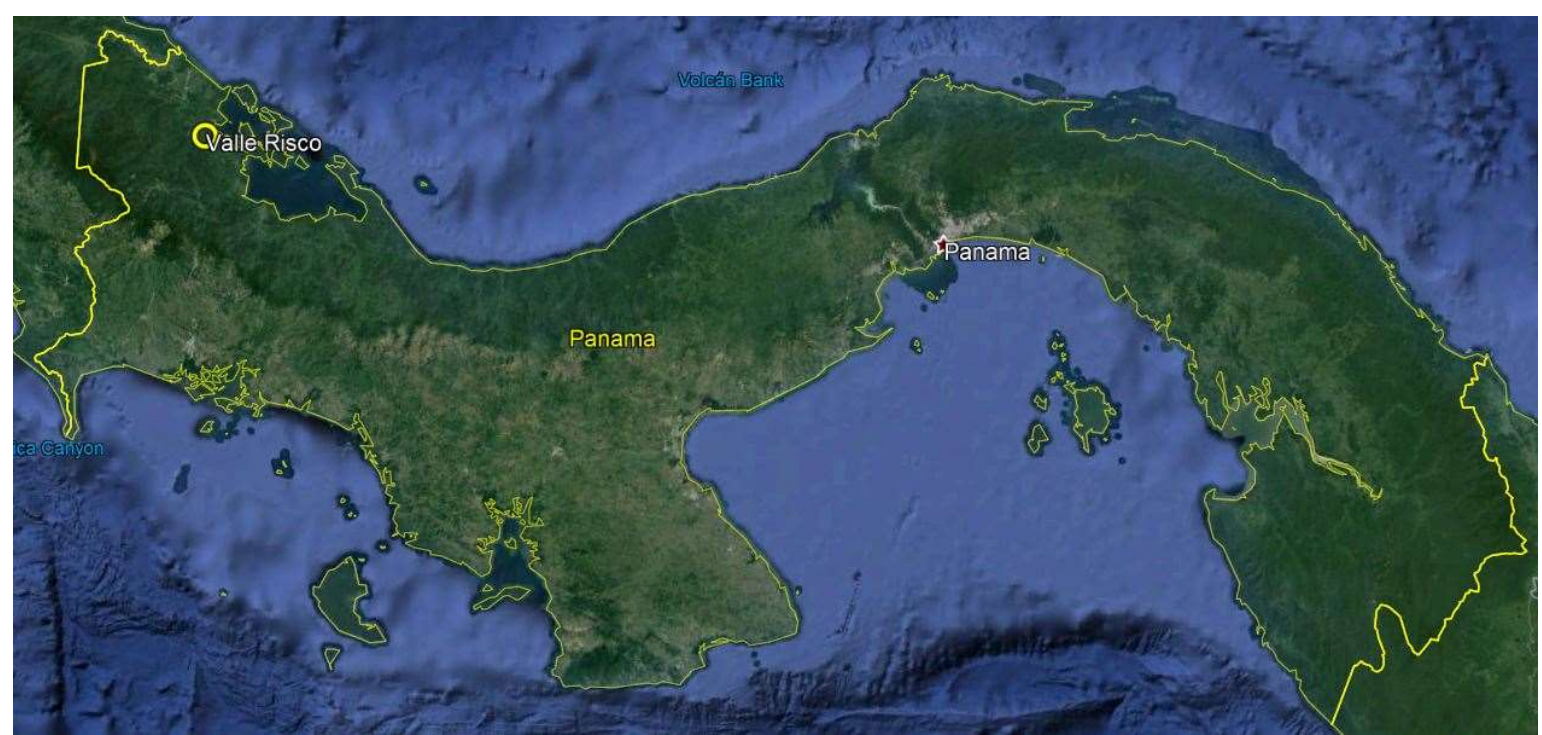

Figure 1 Panama with Valle Risco shown. Image source: Google Maps. See Appendix A for full attribution and copyright licensing information.
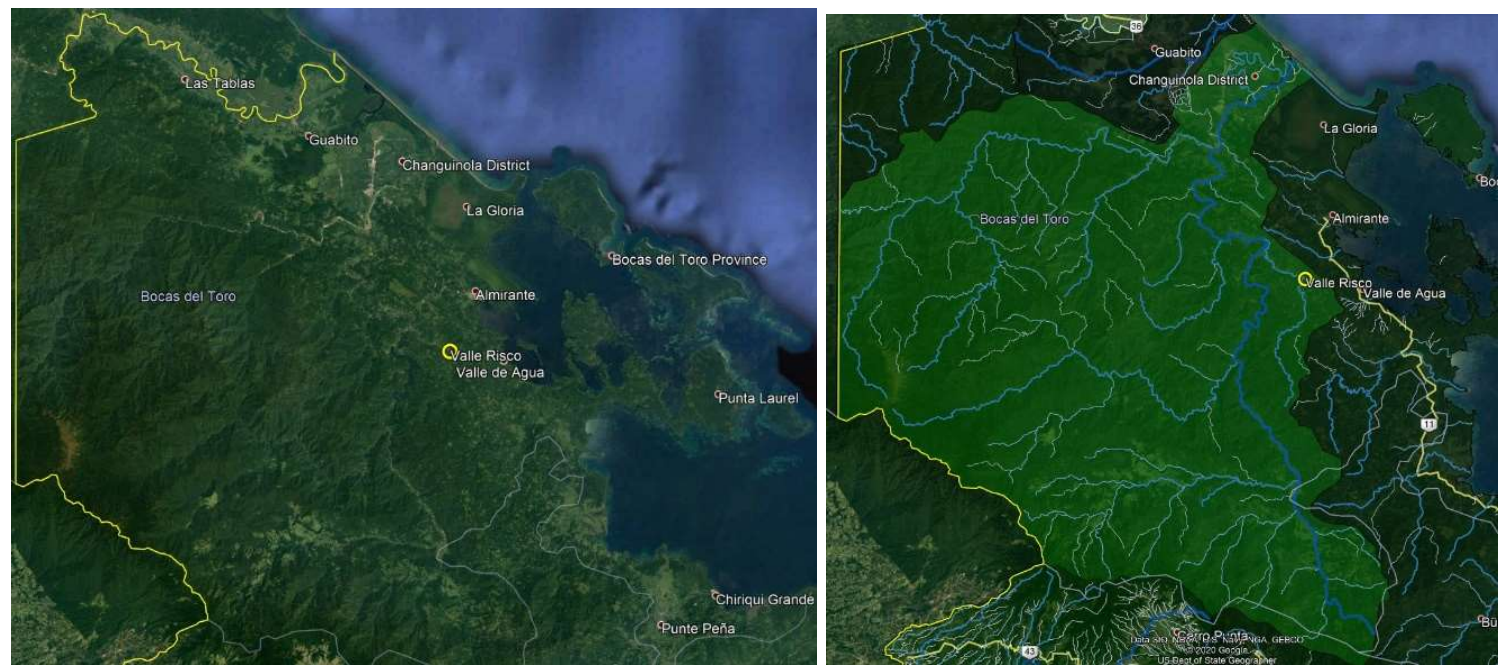

Figure 2 the province of Bocas del Toro showing Valle Risco in relation to other cities (left) and its location in the Rio Changuinola watershed (right). Image source: Google Maps. See Appendix A for full attribution and copyright licensing information. 


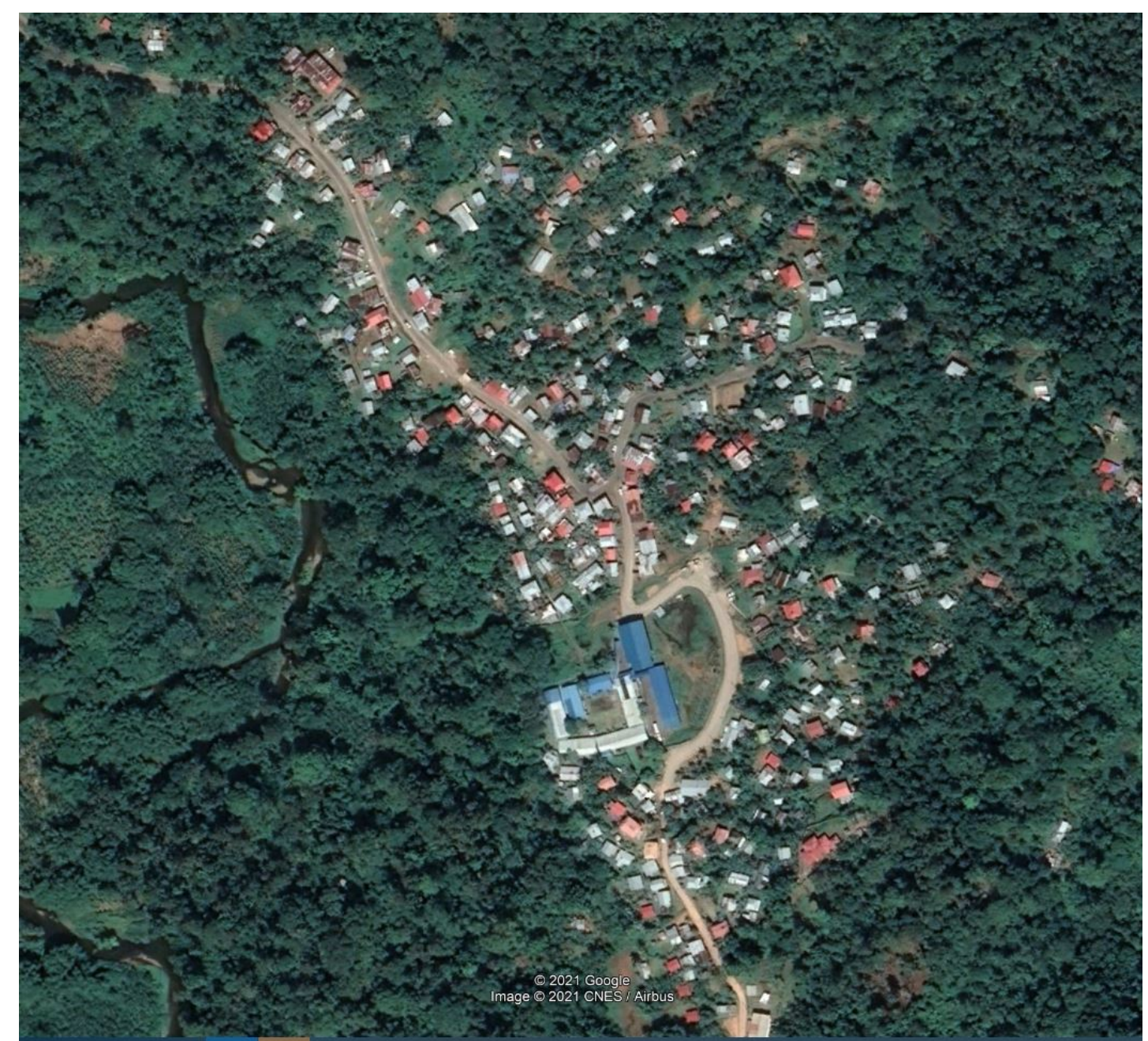

Figure 3. Valle Risco. Image source: Google Maps. See Appendix A for full attribution and copyright licensing information.

Valle Risco strives to establish itself as a permanent influential entity in the region. There is a deep interest in maintaining the culture, language, and traditions of the Ngäbe. To contribute to longevity and establishing itself as a permanent settlement, the locals have planned a number of major development works. These include consistent electricity, a water treatment plant, a wastewater treatment plant, expanding the health center to a hospital, constructing a University of Panama extension. They have already begun a major expansion of the school to include a full high school with laboratory space, a gym, and a library, and expanded the existing road for miles in two directions in order to connect more remote communities. Such major works would surely provide a socioeconomic boost to the community; however, environmental effects of such large endeavors would increase accordingly.

The goal of this report is to compile sources of knowledge regarding watershed science and policy to aid in community decision making with regard to environmental management. A section on indigenous issues provides a more detailed look at ways 
organization of a concerted watershed management effort may be undertaken. This is followed by a review of literature on watershed science for various anticipated physical, chemical, and biological impacts on water quality. These two sections provide the basis for a number of recommendations for development practices to be implemented in Valle Risco and the surrounding communities. They are meant as an overview to describe a process and approach towards better watershed health, and to expand the knowledge base for maintaining a healthy environment while recognizing the vital importance of indigenous sovereignty. The following discussions focus on Valle Risco; however, the content is relevant to the entire Rio Risco watershed. Management efforts should be coordinated between the many surrounding communities in order to ensure equitable decision making and effective natural resource management.

\subsection{Institutional Context}

Various organizations including the Panamanian government have written reports detailing plans for the monitoring and management of surface waters (Table 1). To aid efforts and optimize resources local management efforts should consider these existing aspirational documents. The two main Panamanian agencies with direct activity in maintaining surface waters are the Ministry of Health (MINSA) and the Ministry of Environment (MiAmbiente).

Table 1. Publications by the Panamanian government in the last decade describing efforts in environmental conservation.

\begin{tabular}{|c|c|c|c|}
\hline Document name & Translation & Agency & Year Published \\
\hline $\begin{array}{c}\text { Geo } 2014 \text { Informe } \\
\text { del Estado del } \\
\text { Ambiente }\end{array}$ & $\begin{array}{c}\text { Geo } 2014 \text { Report on } \\
\text { the State of the } \\
\text { Environment }\end{array}$ & $\begin{array}{l}\text { Ministry of the } \\
\text { Environment }\end{array}$ & 2014 \\
\hline $\begin{array}{l}\text { Plan Nacional de } \\
\text { Gestion Integrada } \\
\text { de Recursos } \\
\text { Hidricos de la } \\
\text { republica de } \\
\text { Panama 2010-2030 }\end{array}$ & $\begin{array}{l}\text { National plan for the } \\
\text { integrated } \\
\text { management of water } \\
\text { resources of the } \\
\text { Republic of Panama } \\
2010-2030\end{array}$ & $\begin{array}{l}\text { Ministry of the } \\
\text { Environment }\end{array}$ & 2011 \\
\hline $\begin{array}{l}\text { Plan Nacional de } \\
\text { Seguridad Hidrica } \\
\text { 2015-2050 Agua } \\
\text { Para Todos }\end{array}$ & $\begin{array}{l}\text { National plan for } \\
\text { water security } 2015- \\
2050 \text { water for all }\end{array}$ & $\begin{array}{l}\text { Government of the } \\
\text { Republic of } \\
\text { Panama }\end{array}$ & 2016 \\
\hline
\end{tabular}


In 2014 MiAmbiente released the report "Informe del Estado del Ambiente," which gave an overview of the then current state of environment in Panama, some of the relevant actors working towards environmental stewardship and some of the projections for the coming years. As part of their assessment of surface waters, the agency created a scoring system based on nine physical, chemical, and biological parameters with scores ranging from "highly contaminated" to "not contaminated" (0-100). Within this rating system the report states that water quality in the Changuinola watershed varied with time but was generally between "little contamination" and "acceptable" (51-90). In order to show a more indicative trend in water quality, the report goes on to grade water bodies for each year between 2009 and 2012, showing a steady increase in water quality from a score of 80 to 90 . Regarding the impact of water quality on health, the report mentions a consistently high case incidence of diarrhea as the biggest health impact of water (consistently about 6000 cases per 100000 people). The report ends with a section on actions towards environmental management. Among these are Law 44, which establishes a special administration for the management, protection, and conservation of watersheds in Panama. This law describes a three part plan to maintain water quality through monitoring programs at the watershed level, establishing watershed management plans, and establishing that there should be committees to oversee the implementation of these plans (Autoridad Nacional del Ambiente June 2014).

In the "Plan Nacional de Gestion Integrada de Recursos Hidrologicas," MiAmbiente reviewed the hydrologic resources of Panama in order to construct a concerted national plan to safeguard them. The challenges identified included a diversity of conceptions, cultures, and uses of water among various populations. However, through national campaigns and education this situation is claimed to have improved as an environmental awareness has increased among the population. The plan approaches water from six axes: water sustainability, water and development, water and society, vulnerability and adaption to climate change, institutions and governance of water. The report was formed from the outcomes of various international events including the Global Water Forum, the international conference on water and the environment, and the efforts of various agencies, including the World Bank. In this analysis the country is divided into two main regions, a wet tropical region and a dry region. As Valle Risco is located in the tropical northern region, it experiences a high annual rainfall; however, dryness and drought are expected to increase as the effects of climate change develop (Hoegh-Guldberg, et al. 2018). Reported main sources of water contamination include the discharge of untreated waters from domestic and industrial users, solid waste accumulation, agrochemicals, and deforestation. The government has released a number of technical reports, summarized in Table 2, aimed at avoiding contamination of water resources (Autoridad Nacional del Ambiente 2011). 
Table 2. Technical documents referenced in the National Plan for Hydrological Resources. Each discusses various means of protecting surface waters from the effects of human use.

\begin{tabular}{|l|l|}
\hline \multicolumn{1}{|c|}{ Name of document } & \multicolumn{1}{c|}{ Document Theme } \\
\hline $\begin{array}{l}\text { Reglamento Tecnico } \\
\text { DGNTI-COPANIT 24-1999 }\end{array}$ & Reuse of treated wastewater \\
\hline $\begin{array}{l}\text { Reglamento Tecnico } \\
\text { DGNTI-COPANIT 35-2000 }\end{array}$ & $\begin{array}{l}\text { Discharge of liquid effluent directly to surface waters and } \\
\text { groundwater }\end{array}$ \\
\hline $\begin{array}{l}\text { Reglamento Tecnico } \\
\text { DGNTI-COPANIT 39-2000 }\end{array}$ & $\begin{array}{l}\text { Discharge of liquid effluent directly to wastewater } \\
\text { reclamation systems }\end{array}$ \\
\hline $\begin{array}{l}\text { Reglamento Tecnico } \\
\text { DGNTI-COPANIT 47-2000 }\end{array}$ & Use and disposal of final sludge \\
\hline
\end{tabular}

The national plan for the integrated management of water resources established a rating for the quality of water using the parameters shown in Table 3. Generally, this document outlines the strategy of the country over the subsequent 20 years to conserve and protect national waters. Some key aspects of this approach include the involvement of various tiers of governance including public participation, interagency coordination, and coordination with international entities. It sets out to prioritize the watersheds of the nation and address their problems according to this priority list. Economic strategies are to be implemented including payment for ecosystem services and government grants, as well as education to improve public perceptions and treatment of waters (Autoridad Nacional del Ambiente 2011).

Table 3. Parameters to be measured according to the National Plan for the Integrated Management of Water Resources of the Republic of Panama 2010-2030

\begin{tabular}{|c|c|}
\hline Parameter & Weight \\
\hline $\mathrm{pH}$ & 0.11 \\
\hline Dissolved Oxygen & 0.17 \\
\hline Fecal Coliforms & 0.16 \\
\hline BOD5 & 0.11 \\
\hline Temperature change & 0.10 \\
\hline Phosphates & 0.10 \\
\hline Nitrates & 0.10 \\
\hline Turbidity & 0.08 \\
\hline Total Solids & 0.07 \\
\hline
\end{tabular}


In 2016 the Panamanian government released a multisector plan to revitalize the water resources management of the country between the years 2015 and 2050. This document, called the National Plan for Water Security (PNSH), delineates separately five challenges and five goals for the country. The five challenges are (i) providing $100 \%$ access to safe reliable water for the country, (ii) ensuring the availability of ample water for socioeconomic growth and planning for climate change, (iii) restoring and maintaining the health of the 52 watersheds in the country, (iv) maintaining the growing national water and sanitation infrastructure, and (v) evolving towards a culture of responsible water use. The goals for these challenges are, by 2050 , to have universal access to quality water and sanitary services, water for inclusive socioeconomic growth, water risk prevention, healthy watersheds, and water sustainability. This then motivates a framework by which the country can move towards addressing these challenges and goals. Of chief importance are the formation of an interagency group CONAGUA to carry out the work (Comité de Alto Nivel de Seguridad Hídrica 2016).

A major component of this plan is the focus on sanitary services and water quality management at the watershed level. The plan lists actions to take towards healthy watersheds without delving too deeply into specifics. Among these actions are increasing the capacity for government agencies to test water quality. Unfortunately there are no listed plans for laboratories in Bocas del Toro, indicating that any water quality monitoring would have to continue by other means. The plan mentions the use of watershed committees to carry out the work of watershed maintenance. While much of the watershed specific plans are to focus on reforestation as the means of water and soil conservation, other goals in the plan include (i) better monitoring for water quality and water related disasters, (ii) assessing water resources for continued socioeconomic growth, (iii) developing a culture of water stewardship, and (iv) providing conflict resolution resources for water related conflict and designating authority to government entities and watershed committees to handle them. 


\section{Social Cultural Context}

\subsection{Author's Peace Corps Experience}

On September 7, 2018 I arrived in the town of Valle Risco to serve as a Water, Sanitation, and Hygiene volunteer with the Peace Corps. Main projects involved the organization of community groups to better interact with government agencies. Much of the work coordinated closely with ASAFRI as it is a central community organization. Several people affiliated with ASAFRI asked if I could orient my work towards assisting watershed management. I agreed to write an updated management plan and help inform implementation.

The province of Bocas del Toro suffers from a lack of support from government agencies. As stated by numerous Panamanians in my time in Peace Corps, Bocas is still considered a "North American province". Banana companies have presided over the region for the past 150 years and have been the source of most major infrastructure developments such as railroads, ports, and more recently, roads. As such, it is assumed by many local residents that this has caused a tradition of lack of investment in the province. The province has a lack of government officials to work on projects. For instance, one water engineer is in charge of seeing to the needs of the over 200 registered water committees in the province.

To confront this issue, various water committees in the nearby surrounding communities formed a cooperative in order to ease the burden on agencies (by having fewer entities to manage) and provide a hub to share skills, knowledge, and resources. Unfortunately this project was cut short due to the COVID pandemic before the coalition was able to attempt its first major campaign to test its abilities. In order to be officially recognized and aided by the Panamanian government, water committees must be elected in community meetings and the committee members must sign documents to be sent to the capital to register it. This first project was a plan to galvanize the group and demonstrate its capability in strength in numbers by aiding all surrounding committees to complete this process, the details of which may be unknown to communities. I was evacuated from the country one week before the meeting to organize this project, and the group did not meet in the subsequent 13 months in observance of COVID precautions. Despite this setback there was growing participation in the coalition and a push for a viable means of increasing the validity and operability of community-organized management schemes and obtaining more help from agencies. It is unlikely that the committees have met due to restrictions from COVID as of the writing of this report; however, these coalitions would be valuable stakeholders for water resource management, and may even serve as a model for possible watershed management committees or coalitions. 


\subsection{Brief History of Valle Risco and ASAFRI}

Valle Risco is a small rural indigenous town on the northern coast of Panama in the Province of Bocas del Toro. It is located 8km south of the port town of Almirante on the Atlantic Coast. The town acts as a regional economic and cultural hub for the surrounding communities (Figures $4 \& 5$ ). The population has steadily increased over the past several decades to 2500 people. As access to infrastructure technology and education have increased, the community has found ways to organize to confront challenges in its development.

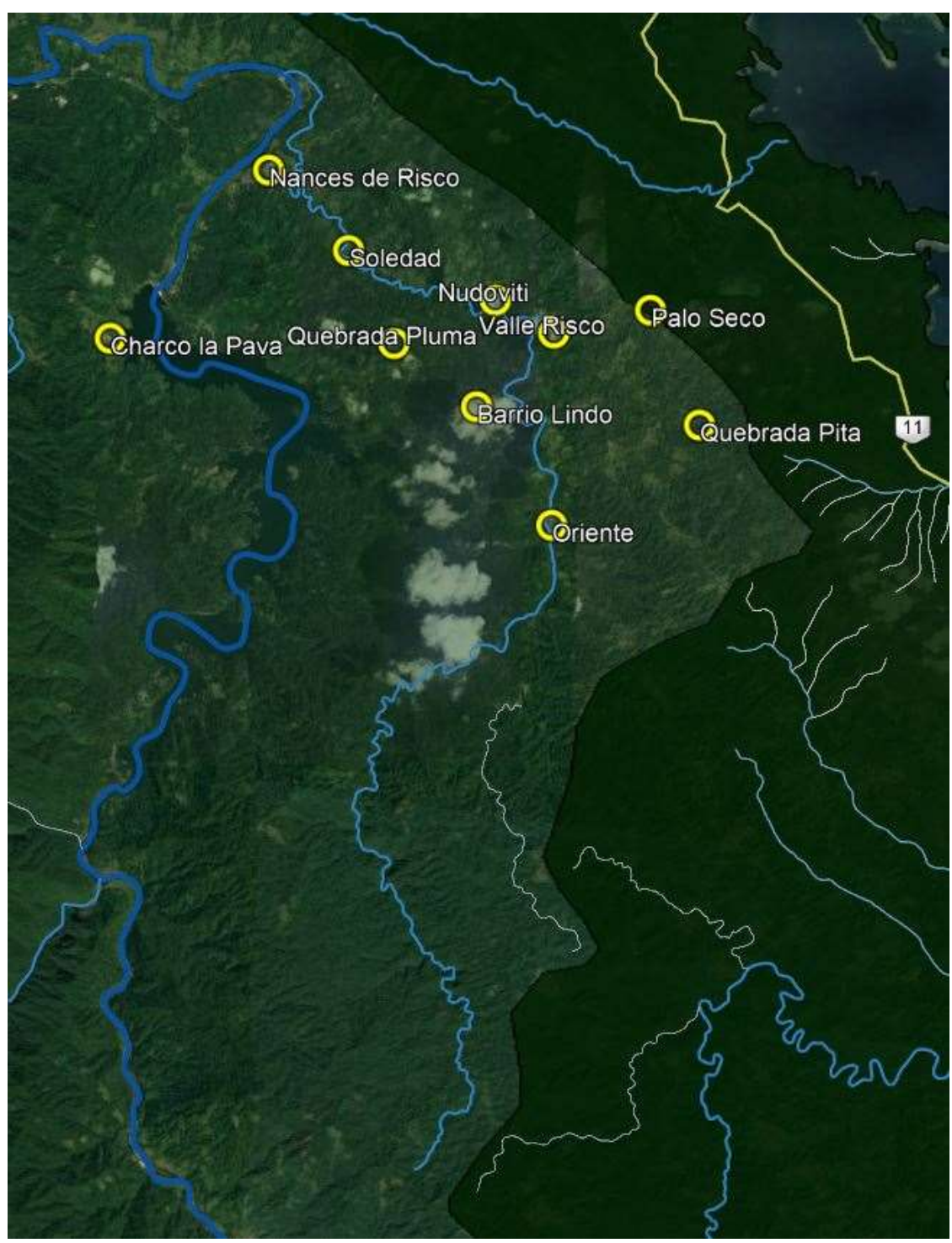

Figure 4. Some of the surrounding communities which connect to Valle Risco. Image source: Google Maps. See Appendix A for full attribution and copyright licensing information. 


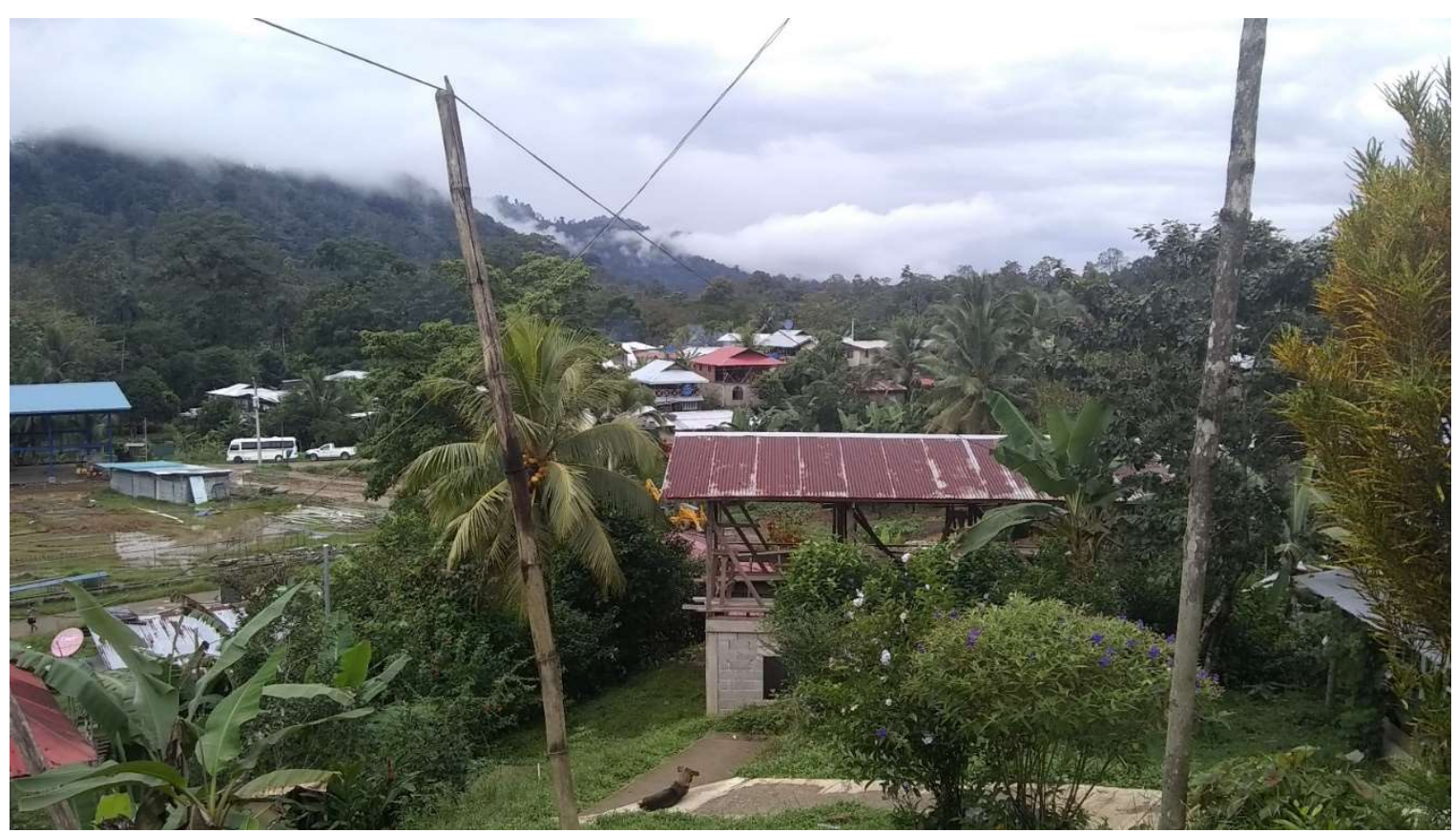

Figure 5. View of the main area of Valle Risco. This is the entrance to the region via a bus stop, holds many shops, and is the location of many cultural events ranging from casual interactions to holiday parades and festivals. Photo by author.

The first Ngäbe inhabitants of the Valle Risco arrived in the area with a guide in 1958, having traveled across the province from the Rio Crikamola in what is now the Comarca Ngäbe-Bugle. In the following year the travelers returned with their families. These three families comprised the beginnings of the town of Valle Risco. With time the population rapidly grew, along with major public works. These included the founding of an elementary school in the 1960s and its expansion over the years to become a complete K12 facility (with current expansions under way, Figure 6), a rural health center to serve the larger rural area, the construction of two main highways into town and most recently connection with electricity. The population is now approximated at 2,500 people. Livelihoods in the town comprised subsistence farming bolstered by some agricultural sales (rice and fruits) when it first was founded. Community members who earned income did so with the banana company in Changuinola. In the 1970s cacao plantations became a source of income, and since then the community has gradually shifted towards the market economy as more members find work in towns and farms in Bocas and the neighboring provinces. 


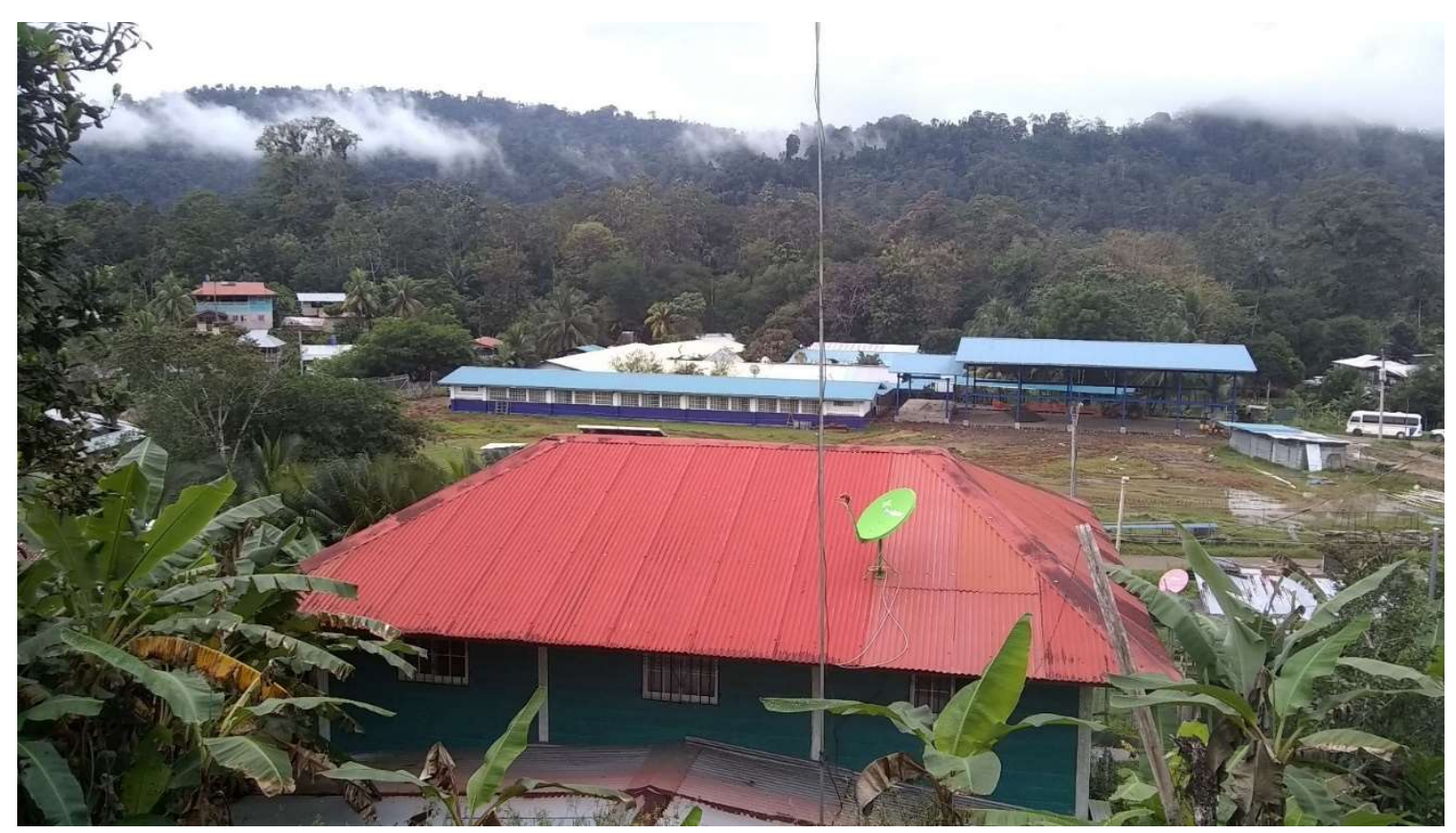

Figure 6. Expansion of the elementary school to include a high school, gymnasium, laboratories, and a library. Photo by author.

As cacao is the main source of income readily available in the area, the earliest recorded community institution is the Agroforestry Association of Valle Risco (Asociacion Agroforestal de Valle Risco, or ASAFRI). The organization was founded in order to unify community farming efforts, bring agricultural trainings into the community, and act as an intermediary to government institutions such as MiAmbiente and MIDA. Community members demonstrate an awareness of environmental concerns, especially related to forest management. Older community members reminisce of a time when the surrounding hills were bare of trees and covered in endless fields of rice, corn, and cows. While much pasture land is still present along the river, the amount has decreased and much of the forest has returned due to reforestation efforts of the communities. Among the trainings provided by ASAFRI are sustainability trainings to use intercropping to extend the viable lifetimes of cacao plantations and align reforestation efforts with economic concerns, and trainings for organic certification.

Recognizing the increasing population and technology of the communities, ASAFRI has focused its attention on better maintenance of the surface water resources of the area. In the past twenty years ASAFRI has worked with various organizations to begin watershed management projects. One of these groups was from a University in Costa Rica which, in 2007, drafted a 200-page watershed management plan. This group explored the sociocultural aspects of watershed management and commented on the urgency of reforestation as the main practice for maintaining watershed health. Other groups drafted plans, but this was by far the most comprehensive one. The plans generally focus on social elements and forestry, and have little say on water quality monitoring. Unfortunately I lost access to this document in the process of evacuating the country. 
The Panamanian election in 2019 brought a number of major changes that directly affected the course of development in Valle Risco. Valle Risco was originally located within the district of Changuinola. The election resulted in the forming of the district of Almirante, which now contains the township of Valle del Risco. This is a smaller district with a closer capital city, meaning the townships have more power to affect development decisions. At the same time, the new administration of Panama began implementation of the program of decentralization. This decentralization program directly funded community development projects by establishing legal recognition of community development committees for registered communities throughout the country and coordinating with them through the township governments. These two major changes expanded the possibilities of growth in Valle Risco and leaders formed a committee to manage major projects. This committee is formally distinct from decentralization as the town of Valle Risco is made of three neighborhoods or barrios, each recognized as an individual community by decentralization. The development committee would thus coordinate development efforts spanning all three barrios. The prospective projects include expanding the school, growing the health center into a hospital, establishing a University of Panama extension in town, and the construction of a drinking water treatment plant and wastewater treatment plant for the entire township. For the last two of these, the water treatment plant would use Rio Risco as a water supply while the wastewater plant would discharge into Rio Risco.

\subsection{Social and Cultural Considerations}

It is the purpose of this paper to describe considerations for an integrated management scheme. There are a number of social topics related to power, knowledge, and indigenous rights that must be considered when implementing integrated management. These topics are relevant for much of the following technical and logistical discussion.

Integrated management is the involvement of stakeholders at various levels of government and organization in the management of a system. Having the help of larger entities can increase access to limited resources and knowledge and assist the coordination of efforts with other groups with similar goals. This course of action carries risk as it involves the balancing of power, since with the ability of resource allocate resources comes power. This can result in a concentration of power in the state and inequitable sharing of resources and means. To avoid exacerbation of existing inequalities, power must be transferred to the local and indigenous communities which live with and in the environments being managed (Floress, et al. 2015). I argue that to avoid issues of oppression, this shift in power to manage natural resources and exercise their rights as citizens must be seated in the indigenous communities that live in the given environment. What considerations may facilitate the coordination of such entities?

A recent example, which emphasizes the importance of more local power in environmental conservation, is state oppression exacerbated by environmental efforts in the construction of the nearby Chang 1 Dam (Finley-Brook and Thomas 2010). The inhabitants of Valle Risco are intimately familiar with this tragic story which resulted in 
the violent forced displacement of several neighboring communities. As part of a carbon trading scheme, Panama allocated a nearby portion of the Changuinola River to be developed into a hydropower dam. Communities were not involved in any meaningful decision making process and were subsequently displaced. This displacement occurred by violent means with the aid of a national police paid by the construction company and resulted in not only the loss of homes and land, but extensive trauma and the splintering of family groups and communal land fundamentally altering the community's relationship with the environment and one another (Finley-Brook and Thomas 2010). This is one example, with which the residents are very familiar, in which state-sponsored activities used rhetoric of environmental conservation and economic growth to further state motives at the expense of the indigenous population. An American company AES was given the freedom to use coercive and violent tactics to rid people of their land and sovereignty so that Panama could benefit from the economic gain of increased hydropower and carbon credits. Third party international organizations were called in to assess the damage done. The families displaced by AES and the Panamanian government still struggle to recover from their trauma and piece their lives back together.

This extreme example shows some of the main problems in power sharing. Community goals and government goals are seldom aligned (Davies, et al. 2013). Colonial entities have defined within their societies what it means to be indigenous. These connotations range from assimilation such as "colorblindness" to othering (Jordan-Ramos 2010). Often times these definitions serve a utilitarian purpose for governments who use these definitions as a means for control. Colonial entities have long sought the natural resources in lands where indigenous people live. Infrastructure and development are thus only implemented when they benefit the colonial state (Jordan-Ramos 2010). When governments do provide development, it may take the form of performative displays of modernity or else a means to other ends that the government seeks, instead of an improvement in quality of life for the so called stakeholder (Maddox 2017, Larkin 2013, Hetherington and Campbell 2014). Infrastructure can exist as a symbol of the modern (Larkin 2013), a concept which defines the state as a provider of progress as defined by colonial capitalist paradigms. Such fixation on a modern future defines indigenous people as belonging to the past. Thus in their receipt of state defined development indigenous people are made subjects of the state and homogenous with the rest of its subjects (Maddox 2017). The other example stated here is that of providing development as a means to other ends. A road in a remote, rural town may go unpaved until the colonizer recognizes potential resources, such as wood or energy sources, may exist beyond. Thus what may seem like benevolent development of municipal services such as roads and electricity may be the development of infrastructure to exploit resources, the profits of which the local inhabitants may likely never see (Maddox 2017). This exploitation is facilitated by colonizer definitions of "development", and to confront this I propose that indigenous concepts of the idea are adopted for the framework of goal setting.

Furthermore, the western distinction between categories of what is scientific, cultural, and productive may not exist in many indigenous ontologies (Hill, et al. 2012, Davies, et al. 2013). Thus, whereas a government may make a distinction between a cultural benefit and a livelihood benefit, an indigenous culture may see such distinction as nonexistent. 
Furthermore management plans must be living documents which are able to react and adapt to changing conditions (Davies, et al. 2013). Past experiences show that in disaster situations local environmental knowledge is key to efficient, effective, and equitable response, while heavy-handed government action can be slow, ineffective, and serve to consolidate power and reinforce oppression (Marchezini 2015). Indigenous populations are in some instances more effective at resilience and adaptation (Apgar, et al. 2015). This leadership and ability does not imply that the group should be left to work on their own, as the state has more access to resources and logistics. Governments often use reasoning such as claiming "local ownership" as a means of absolving responsibility (Moriarty, et al. 2013).

In more recent history, ecological initiatives have taken the form of top-down policy implementation (Hill, et al. 2012). This approach privileges western science as the dominant knowledge building process. In the BPPS, ecological conservation has often looked like "paternalistic plans to teach Ngöbe inhabitants to live sustainably in the reserve through a park ranger training programme and the creation of community tree nurseries" (Finley-Brook and Thomas 2010). Generally this approach neglects an entire history and culture which has adapted to understand ecologies. Traditional ecological knowledge (TEK) is being incorporated more and more into conservation and management efforts. TEK refers to the use of indigenous philosophy as a starting point for understanding nature. It goes beyond a mere cultural utilitarian perspective and encompasses how humans relate to nature and each other (Nelson and Shilling 2018). On top of constructing meaning rooted in indigenous means of knowing, it also establishes how goals and purpose are defined. Power can further be yielded by governments by high transparency of data collection. Knowledge and trust can be gained when no one method of knowledge generation is privileged, and when knowledge generation can be a shared process (Adler and Birkhoff n.d.).

Much community-organized infrastructure in Panama and Valle Risco has taken the form of operating committees. They all have the general structure of 7 members (president, vice president, secretary, treasurer, "fiscal", and two "vocales"). This is how Valle Risco has learned to operate projects. For example at the onset of major development plans in town they established a development committee as seen in Figure 7. A watershed committee could provide a single entity in the community to coordinate management efforts as well as coordinate with other committees and the national government. This is one potential means of placing power in the hands of the community. The effectiveness of committees is dependent on access to resources as well as the decisions of the committee members. Without the ability to back decisions with actions, committees have little meaning. Committees in Panama have dissolved when the backing of government resources and planning have fallen short. Likewise, in the absence of payment and perceived self-efficacy combined with high expectations, committee members may grow resentment. ASAFRI has been effective in coordinating resources for farmers and other community members as well as mobilizing people for conservation efforts such as community trash pickups. Such an entity may prove appropriate for this situation; 
however, the preceding discussion may serve to anticipate pitfalls. Committees may act to consolidate power and exacerbate already existing inequality (Floress, et al. 2015).

As regional, national, and global politics continue to change, a variety of strategies will emerge in Valle Risco to handle government and corporate interest and work for indigenous sovereignty. There are a variety of perceptions and strategies among the inhabitants of the region and varying levels of trust in, and cooperation with, the government. While some communities take an approach of complete separation from government activities, others read stacks of legal documents and win elections or regional and district offices. A common story in newspapers while I was in Panama was the talk of using public-private partnerships in implementing decentralization. This could heighten the presence of corporations involved in shaping the built environment around Valle Risco. Meanwhile, more young community members leave to work in farms and cities, sending money home to build houses for their families.

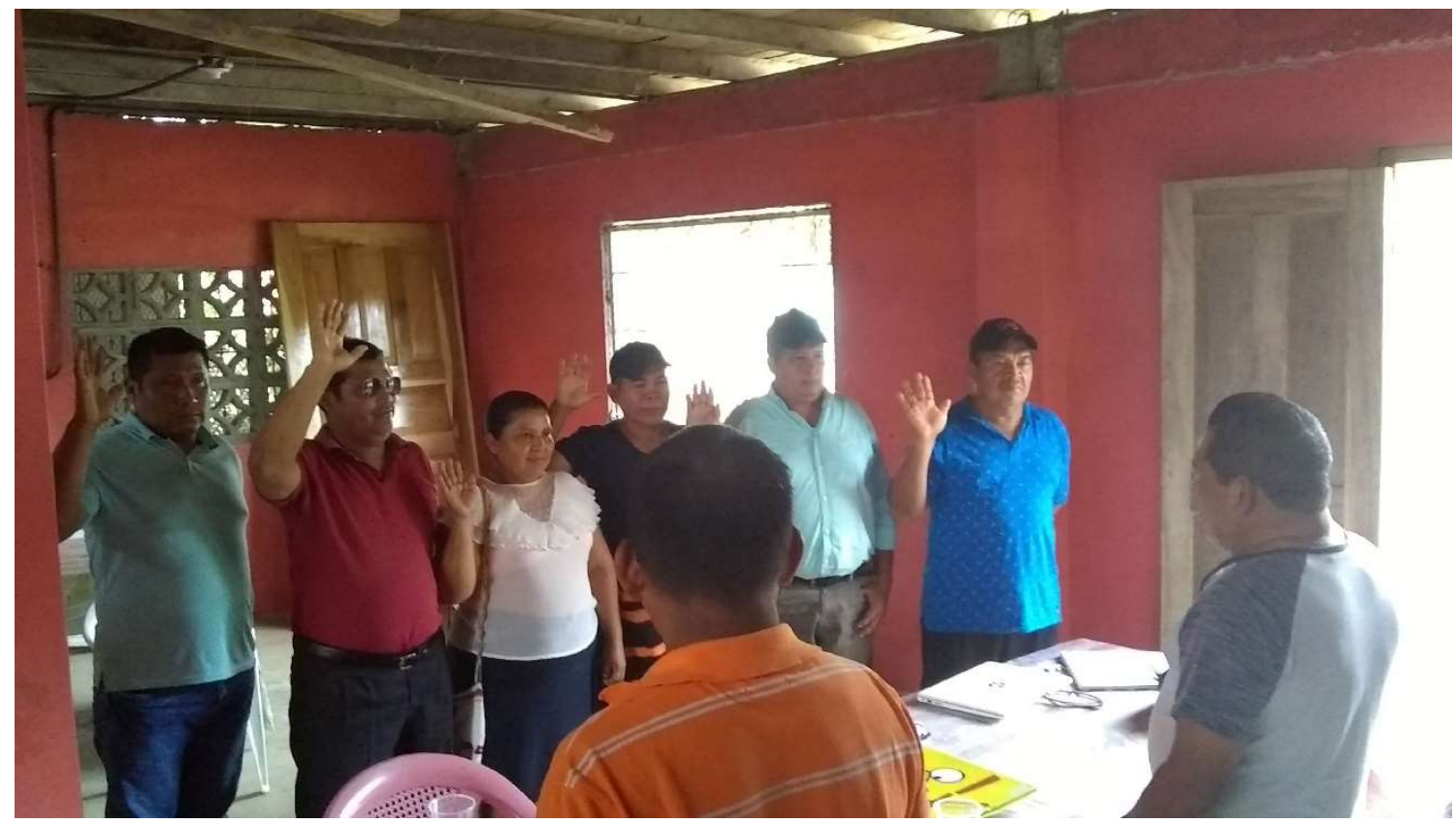

Figure 7 Picture of Valle Risco development committee being formed. Photo by author. 


\section{Technical and Logistical Considerations}

A general review of literature regarding scientific and engineering aspects of watershed management is presented. This discussion is divided into four broad sections: wastewater, drainage, monitoring, and ecosystem services. The intent is to cover broad yet relevant information to lay a groundwork for the importance of each element of watershed management and to inform the subsequent recommendations at the end of this report.

In order to inform policy and management decisions, there must be an understanding of the present environmental quality as well as a target environmental quality to be achieved or maintained. Water quality can be analyzed for physical, chemical, and biological contamination. Fecal contamination is a major health concern and a widespread issue in the area. Excessive runoff, erosion and sedimentation are also concerns during and following storm events, while maintenance of clean and abundant water supplies is a year-round priority.

\subsection{Wastewater Management}

Wastewater is one of the main sources of health issues in much of the world. Where communities lack proper sanitation services, they regularly deal with illness that can prove fatal if not treated properly. Rural populations often use pit latrines when the means of construction are available. In the more densely populated areas where there is greater access to resources, families use septic tanks. While this presents a benefit to health, there are still concerns regarding surface water quality. A study of septic tank systems influencing surface waters in Georgia, USA found that higher concentrations of septic systems in a humid and warm climate resulted in higher fecal contamination of streams (Sowah, et al. 2014).

According to a community survey conducted as part of my preliminary Peace Corps work (Appendix B), the population of Valle Risco is increasingly implementing flush toilets with rudimentary septic tank systems when available, but more commonly seepage pits or cesspools (Figures 8 \& 9). These septic tanks consist of a buried cinderblock-lined chamber or pre-manufactured plastic tank with an outlet leading to a ditch. In some cases the flush toilet may lead directly to a receiving ditch. While flush toilets and septic systems may offer health benefits, they can also lead to increased health risk and environmental degradation when poorly implemented. 


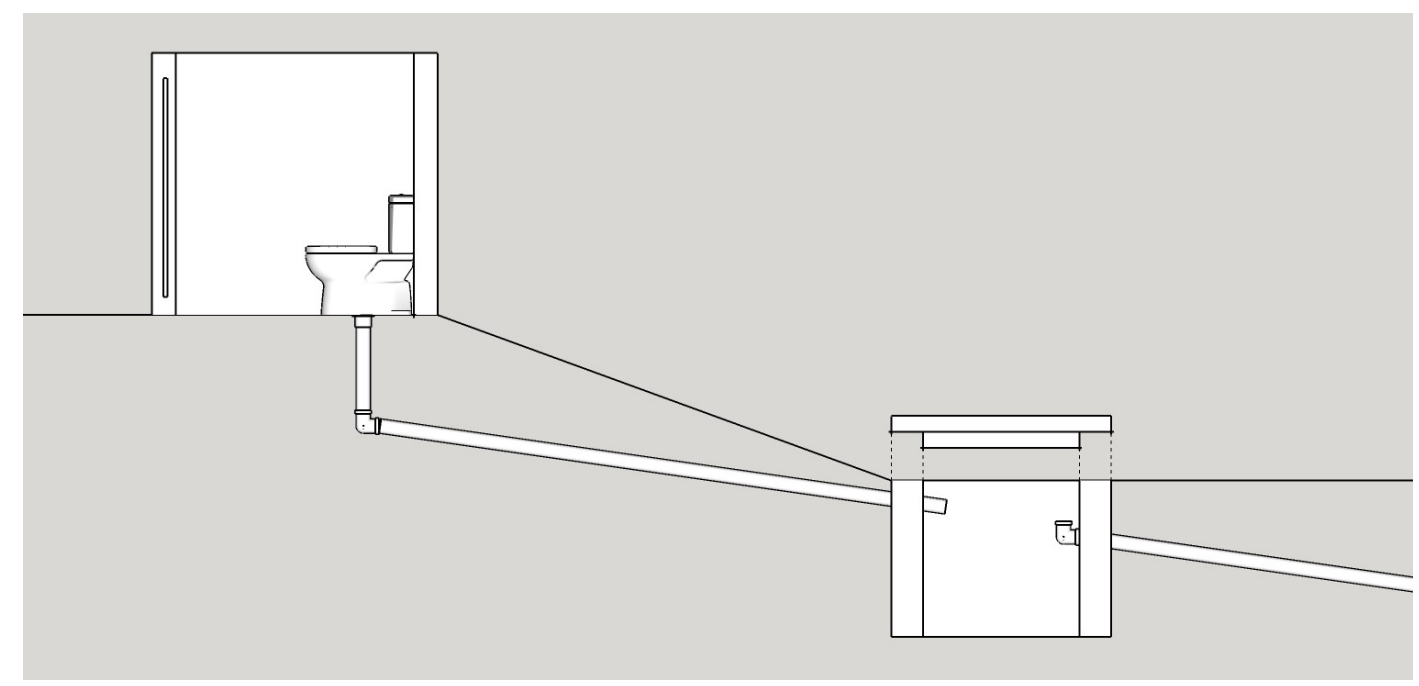

Figure 8. Sketch of common seepage pit system. A flush toilet leads through 3"-4" PVC pipe into a pit lined with 8 " cinder block. An overflow leads to either another pit or a drainage ditch/creek. Made by Author using SketchUp 2017.

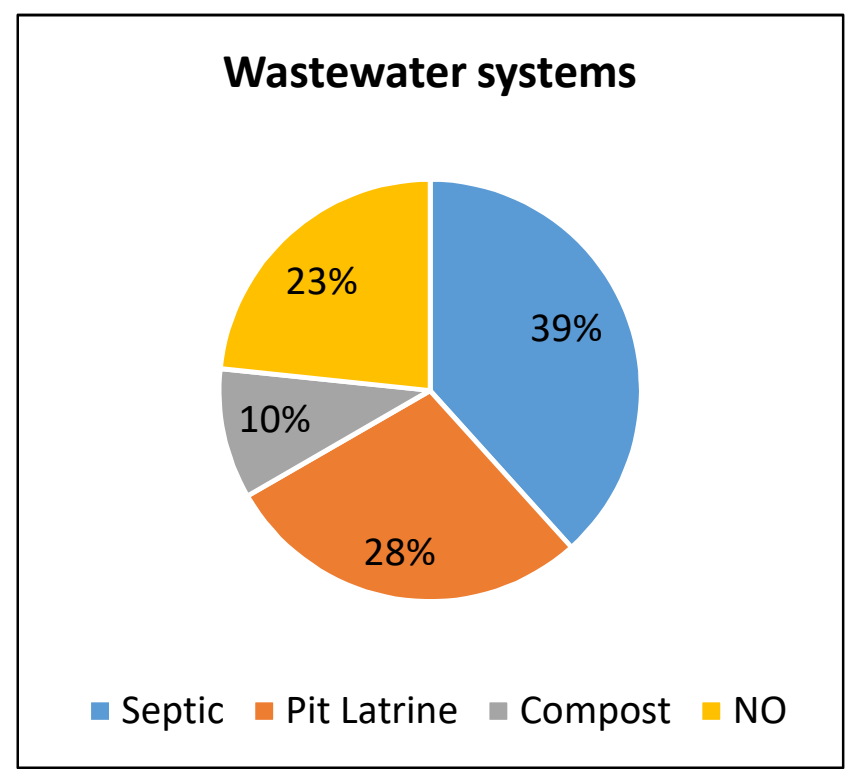

Figure 9. Results of a survey of wastewater approaches in Valle Risco. This demonstrates the increasing prevalence of flush toilet systems referred to by locals as septic systems but includes seepage pits. Compost indicates composting toilet; NO indicates no system installed. Data collection by author.

Among the desired infrastructure expressed by in the leadership of Valle Risco is a community-scale wastewater treatment plant. While the rapid development and prevalence of flush toilets would merit an advanced centralized treatment technology, a single conventional treatment system might not be an appropriate technology for the given conditions, at least in the near future. Conventional wastewater plants are designed to handle wastewater at a specific loading rate and with specific characteristics. Furthermore, they can be costly and rely on constant access to power and maintenance. 
Capital and recurring costs would be high, and the growing population could render an expensive system obsolete in a short amount of time, requiring increased investment. Lower cost and lower maintenance systems exist which can potentially achieve equivalent treatment effectiveness without requiring the same level of energy or maintenance. Two such systems, wastewater treatment lagoons and artificial wetlands, are discussed here following a brief discussion on the collection system.

The creation of any centralized waste treatment system would require a collection system and additional maintenance of infrastructure. The hilly topography of Valle Risco causes difficulty in the use of septic systems as a collection system technology. This difficulty increases as the population increases filling in spaces between houses and thus limiting viable area for septic tanks. While regulations vary among locations, it is recommended that at least 50 feet be allowed for spacing between septic tanks and housing units (USEPA 2002). For the continued use of septic systems, it is recommended that multifamily systems be considered. These would have larger receiving tanks which would service multiple households allowing for less use of space. Fewer tanks could then be connected to a centralized collection system which would lead to a centralized treatment works such as a lagoon or a wetland. This hybrid systems could be managed at the community level and provide preliminary solids separation for the treatment system. Conventionally, septic systems are emptied by pumping truck and the waste is transported to the nearest wastewater treatment plant capable of handling septic waste. The nearest wastewater plant to Valle Risco is an hour drive away in Changuinola.

Wastewater lagoons are shallow artificial ponds designed to hold large quantities of wastewater. These rely on algae and other microorganisms to consume and break down wastewater constituents. In general, there are two kinds of processes in treatment lagoons: aerobic and anaerobic. Lagoons can be designed to implement either type of process, or both. Anaerobic lagoons are lagoons which operate in the absence of dissolved oxygen. In this kind of lagoon two kinds of bacteria process incoming wastewater. A first kind of bacteria breaks raw wastewater into nutrients, carbon dioxide, organic acids, and water. A second kind of bacteria ferments organic acids into methane and other compounds (Water Programs, Sacramento State 2019). These lagoons require less space than other systems and are used to process high influent biochemical oxygen demand (BODs) (Mihelcic and Zimmerman 2014). BOD 5 is an aggregate measure of water quality which measures the amount of dissolved oxygen consumed by biological decomposition of chemical constituents contained in the water (Metcalf \& Eddy Inc, et al. 2014). The process is used in some areas to capture methane and provide fuel to households and businesses (USEPA 2020). Methane capture would require an enclosed system and would increase maintenance needs. Aerobic lagoons are lagoons which operate in the presence of dissolved oxygen. The functional ecosystem is a cycle of bacteria and algae. Bacteria feed on nutrients contained in wastewater producing carbon dioxide which is used by algae in photosynthesis. The photosynthesis, in turn, produces oxygen which is used by the bacteria (Water Programs, Sacramento State 2019). Aerobic lagoons often require more management and funding, as aeration is often achieved by mechanical stirring or air pumping (Mihelcic, Fry, et al. 2009). Facultative lagoons are a combination of the two kinds of lagoons in one pond. They are some of the more 
common lagoons used and, when maintained properly, can achieve high effluent water quality from 70\%-90\% BOD (Mihelcic, Fry, et al. 2009, Water Programs, Sacramento State 2019).

Finding suitable area for the placement of a lagoon is one of the challenges of this technology. To demonstrate, the sizing of a lagoon is shown following design considerations of Mihelcic, Fry, et al. (2009). Common temperatures during daytime in the region are around $80^{\circ}-90^{\circ} \mathrm{F}$ going down to $60^{\circ}-70^{\circ} \mathrm{F}$ at night. This temperature range is ideal for lagoon functioning (Mihelcic, Fry, et al. 2009), and ample daytime sunlight facilitates algae growth (Mihelcic and Zimmerman, 2014). The main component of such a system would be the facultative lagoon. The current population of Valle Risco is approximately 2500 people. From my Peace Corps training, water systems in Panama were to be designed to handle $30 \mathrm{gal} / \mathrm{capita} / \mathrm{day}$. This results in a total flow of 75,000 gpd $\left(284 \mathrm{~m}^{3} / \mathrm{d}\right)$. A lagoon with a hydraulic detention time of 100 days requires a volume of $28,391 \mathrm{~m}^{3}$, which, if built to a depth of $1.3 \mathrm{~m}$, covers an area of $21,839 \mathrm{~m}^{2}$ and receives a surface loading rate of 0.5 inches per day. Figure 10 shows an area of similar size to this lagoon near Valle Risco. A complete system would likely include pretreatment and maturation ponds before and after the facultative lagoon, respectively. A pretreatment lagoon would be an aerobic lagoon intended to remove high influent $\mathrm{BOD}_{5}$. These ponds are more generally for systems treating industrial influent (Mihelcic, Fry, et al. 2009). A maturation lagoon is a lagoon intended to provide further removal of nutrients and pathogens (Mihelcic, Fry, et al. 2009, Mihelcic and Zimmerman, 2014). Such a system is designed for the full population of the main center of Valle Risco. There is significant room for variability on this estimate. On the lower end, the full population might not connect to the system at once, causing a deficit of inflow. On the high end, neighboring communities would likely want to connect to the system as well, resulting in a design for as many as 5000 people or more. 


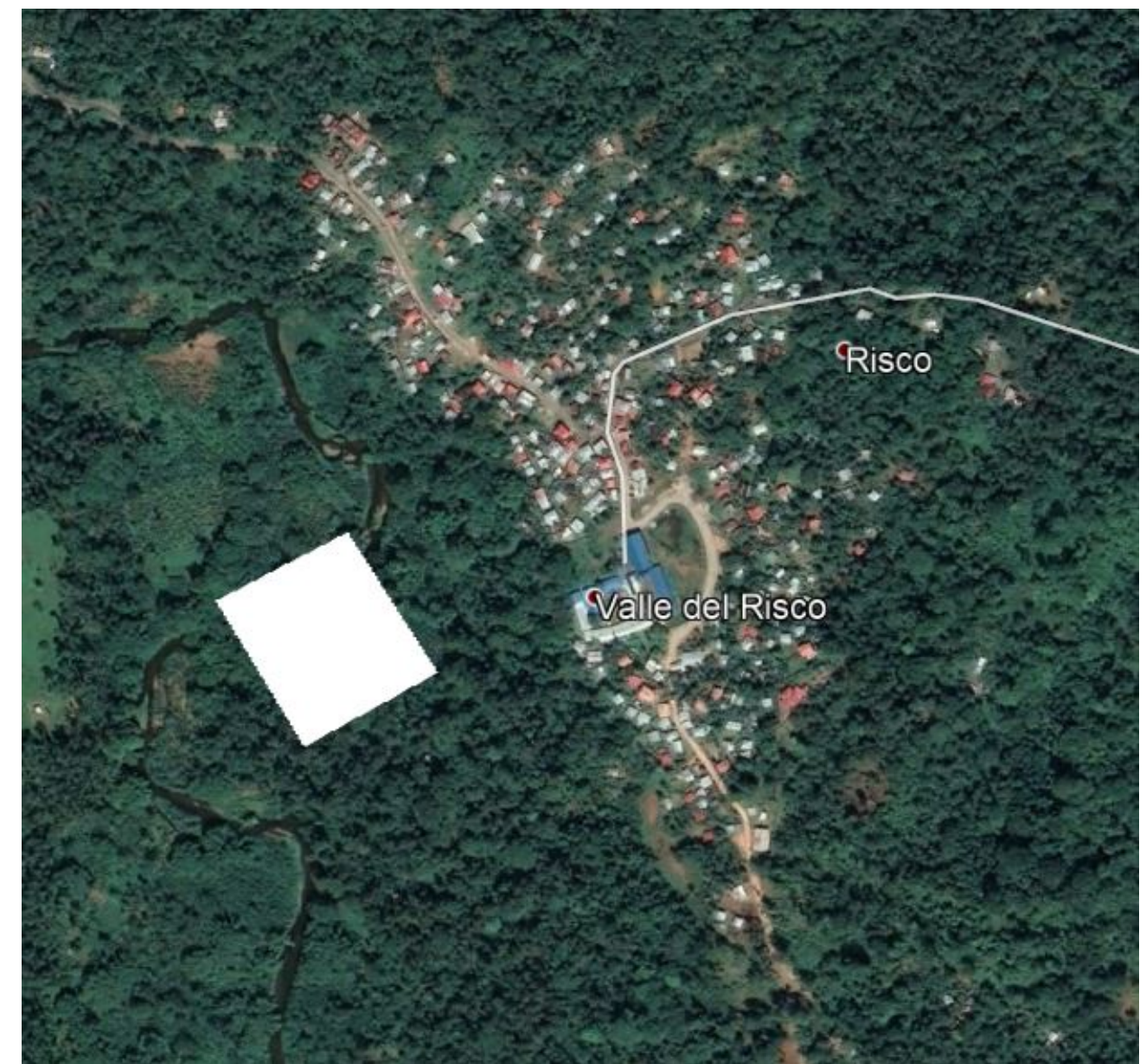

Figure 10. A white square of approximately $21,866 \mathrm{~m}^{2}$. This image is intended only to show the land necessary for for a facultative lagoon as compared to the size of Valle Risco. The location of the white square in the image is on a river bed, and a wastewater treatment system should not be placed here. Selecting a site for such a system would be an important discussion that should include many stakeholders. Image source: Google Maps. See Appendix A for full attribution and copyright licensing information.

Constructed wetlands are an efficient low-tech means of wastewater treatment which recreate natural processes found in wetland ecosystems. While design specifics can vary according to geographic location, population, and treatment objectives, there are two main categories of wetlands based on flow location. These are free water surface (FWS) wetlands, where the surface of the water is exposed to air and flow occurs through the stem and leaf areas of plants; and vegetated submerged bed (VSB) wetlands, where water flows through a porous medium such as gravel. As water passes through the plants and media, physical, chemical, and biological processes treat wastewater at comparable rates to conventional wastewater treatment systems. While specific species are usually planted as part of designs, other plants, which are not part of the designed system, may take root in constructed systems. These unintended plants may have a beneficial or detrimental effect, and as such support the need for skilled monitoring and maintenance (USEPA 2000). 
Lagoons and wetlands may offer a more appropriate technology for the rural area; however, these systems would still require regular maintenance and oversight. An unmanaged system could face a myriad of problems. The operations and maintenance of lagoons and wetlands are generally similar as they involve passive systems. Human intervention is mostly for the prevention of more serious irreversible problems (USEPA 2000). Treatment requires regular testing to ensure the continued adequate operation of systems. For instance, lagoons should receive daily observation of water color and odor as well as weekly measurement of $\mathrm{DO}, \mathrm{pH}$, temperature, and potentially other parameters to monitor lagoon process and whether troubleshooting is needed (Water Programs, Sacramento State 2019).

Both wetlands and lagoons are commonly built using dykes to contain water. These mounds must be regularly maintained by controlling vegetative growth (both mowing the mounds and preventing vegetation growth along the shore). Vegetative growth may allow for infestation by pests such as mosquitoes or rodents. Mosquitoes may carry disease while rodents would build dens in the mounds, weakening their structural integrity (USEPA 2000, Water Programs, Sacramento State 2019). In the case of constructed wetlands, while it is still necessary to mow the retention structure, vegetation is part of the treatment process and thus cannot be removed. In such cases insect populations may be controlled by introducing fish populations or by the use of submerged beds which avoid free standing water altogether (USEPA 2000). In extreme cases, chemical insect and weed control may be implemented; however, this should be avoided for risk to human health as well as risk in impeding microbiological processes (Water Programs, Sacramento State 2019). In both lagoons and wetlands water levels should be monitored to ensure adequate flow for processes. Low water levels may indicate a leak or too much effluent for the level of influent (USEPA 2000). Similarly, influent water quality should be monitored to ensure the system is adequate to treat the incoming raw wastewater (Water Programs, Sacramento State 2019, USEPA 2000). Sludge handling is a different process in each system. Lagoons are able to process sludge to some extent, however they will steadily fill up with time. Lagoons receiving untreated wastewater should be checked yearly for sludge buildup to be eventually removed (Water Programs, Sacramento State 2019). Constructed wetlands, on the other hand, are unable to process incoming sludge and wastewater must have solids settled before going to wetland treatment (USEPA 2000).

Finally such a system would require a surrounding fence to keep wildlife out as they may damage retention structures and impede treatment process. Lagoons further present a hazard to humans if they fall in, and thus only authorized personnel should be permitted in the premises. As odors and insect infestation are to some degree inevitable these systems should be place relatively far away from human populations. This creates further challenges in siting as, not only is a great deal of space needed for these systems (Figure 10), but the surrounding topography is very hilly making flat land sparse and potentially requiring pump stations to move sewage to the treatment system.

The water supply systems of Valle Risco can serve as an indicator for the implementation of community-organized and managed infrastructure. Over the past two decades, three 
water systems have been constructed and maintained to varying levels of functionality. Persistent issues continue to be slow response to damage in the system, community resistance to payment for water services, and limited access to resources and technical training. It is worth considering that these same issues would present deleterious effects to wastewater collection and treatment systems. Before implementing any large-scale centralized wastewater system, the community should deeply consider whether it is capable of effectively managing the resource and what the buy-in of the community will be (Keraita, Drechsel and Amoah 2003). In a study on community-organized water systems, Moriarty et al. (2013) recommended the professionalization of the role water system operator. This would incentivize a single person to remain available for the job, develop their skills and knowledge of operating systems, and provide a single point of contact and accountability for the continued functioning of the system.

\subsection{Stormwater Drainage}

The province of Bocas del Toro receives an average annual rainfall of $3700 \mathrm{~mm}$ (Paton 2020). According to the locals there is little discernable seasonal variation. From my experience, rain falls most days in Valle Risco, with some variability in the duration of rainfall (Figure 11). However, the climate is changing. During my time in Valle Risco, the region experienced an unprecedented drought when little to no precipitation fell over the course of three months. Locals, who had lived in the area for $50+$ years, claimed to have never seen such a drought. Despite this recent drought, and the possibility of increased dryness in general due to climate change (Hoegh-Guldberg, et al. 2018), the region experiences a great deal of rainfall throughout most of the year. This heavy rainfall, combined with the steep topography and clay soils, requires management of stormwater runoff as the area develops (Figure 12).

Valle Risco is built around a number of creeks and ditches which flow into Rio Risco (Figure 13). Runoff accumulates in the nearby hills and flows through town. Some lengths of this flow are routed by the inhabitants to avoid houses which, when combined with runoff from impervious surfaces such as roofs, causes ditches to form. These ditches and creeks run behind groupings of houses where they may also receive greywater from household sinks and showers and, in some cases, overflow from septic tanks or direct input from flush toilets. The ditches and creeks then merge into larger streams (Figure 14) and flow eventually into the river. Many times, livestock are raised directly adjacent to creeks to allow easy access to drinking water (Figure 15). As can be seen in Figure 16, a great deal of pollution can accumulate in these waters. 


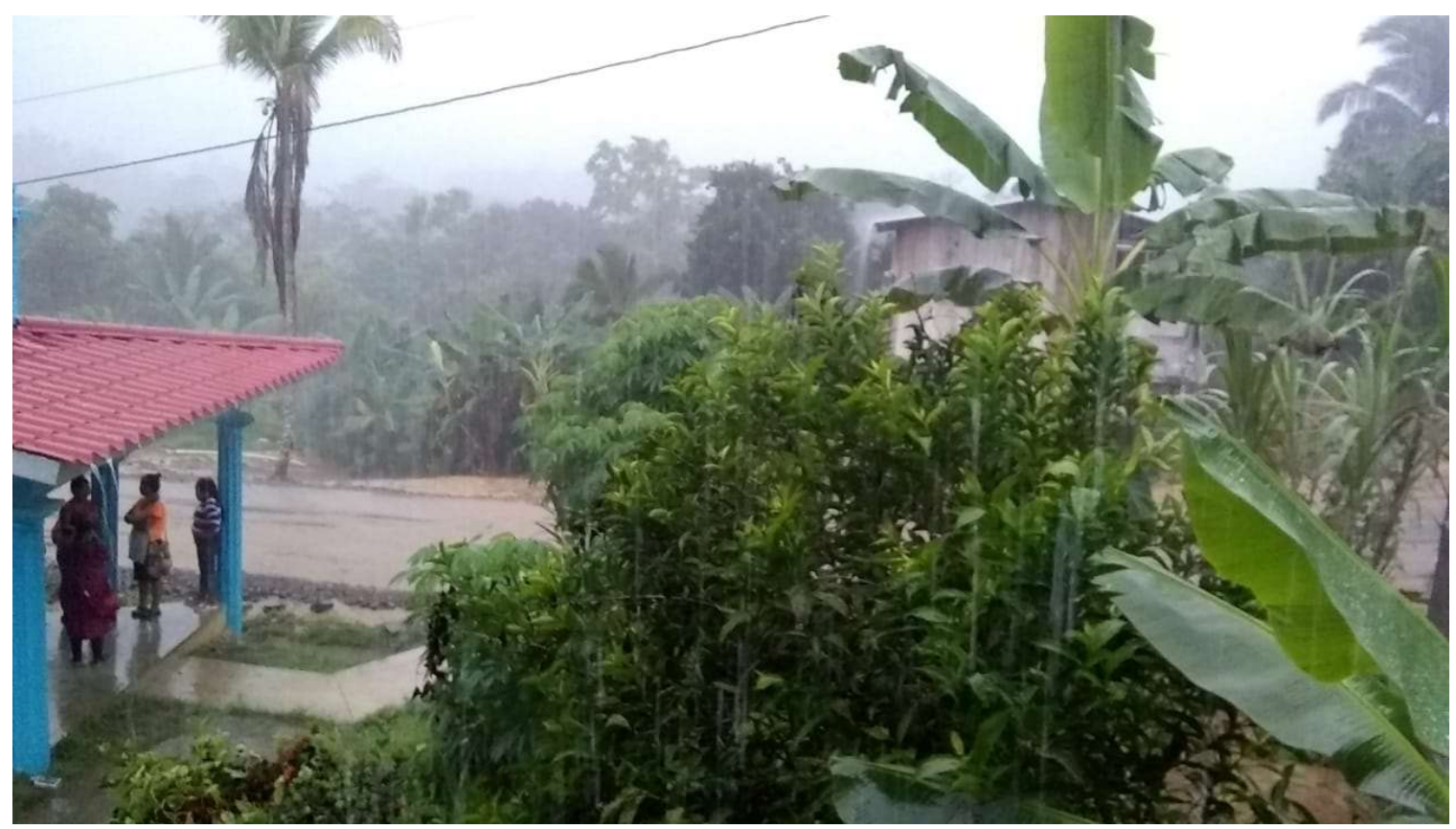

Figure 11. Typical rainfall in Valle Risco. Such storms may last anywhere from 30 minutes to several days. Photo by author.
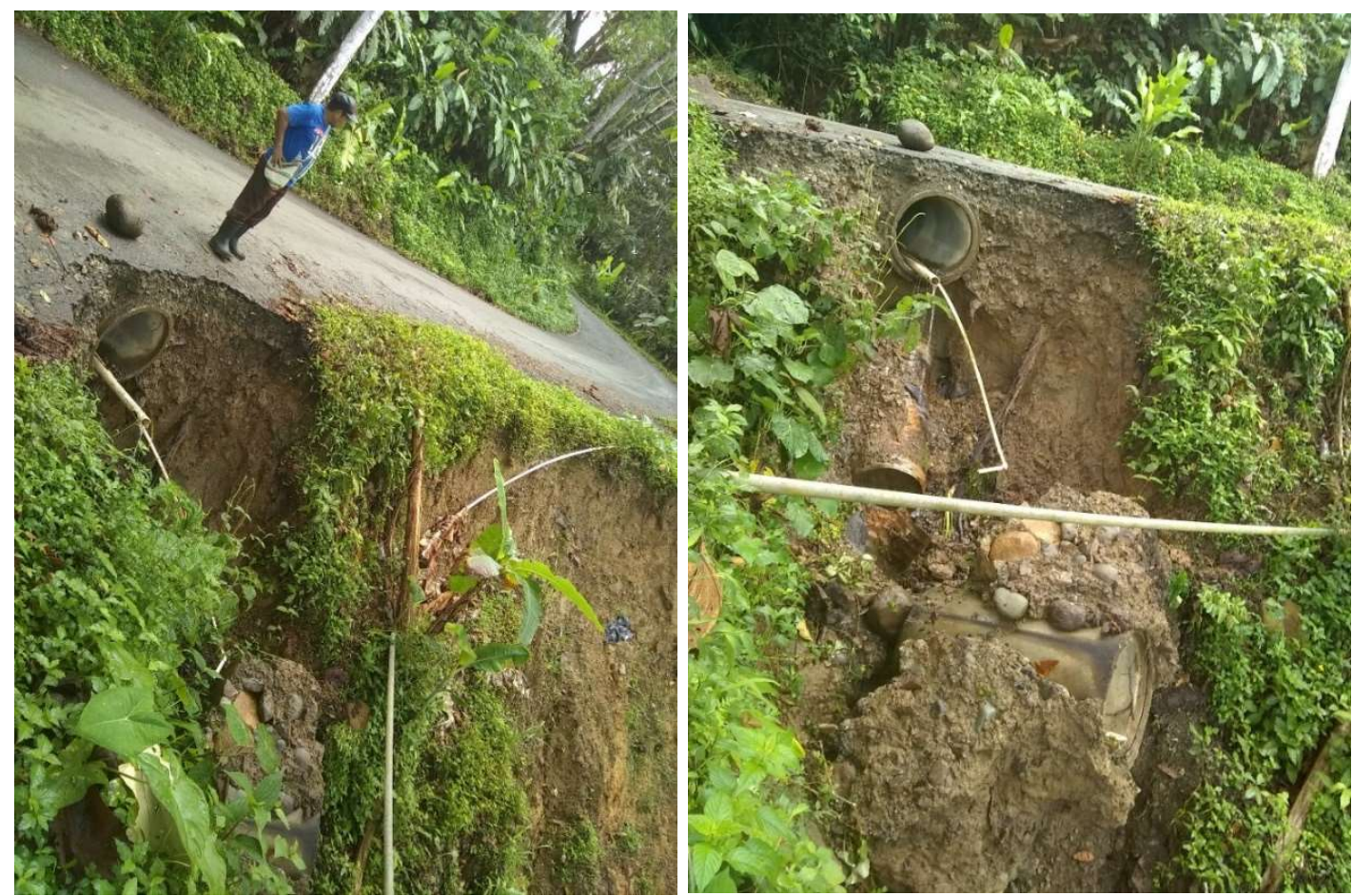

Figure 12. A portion of the road into town washed out due to heavy rain. Photos by author. 


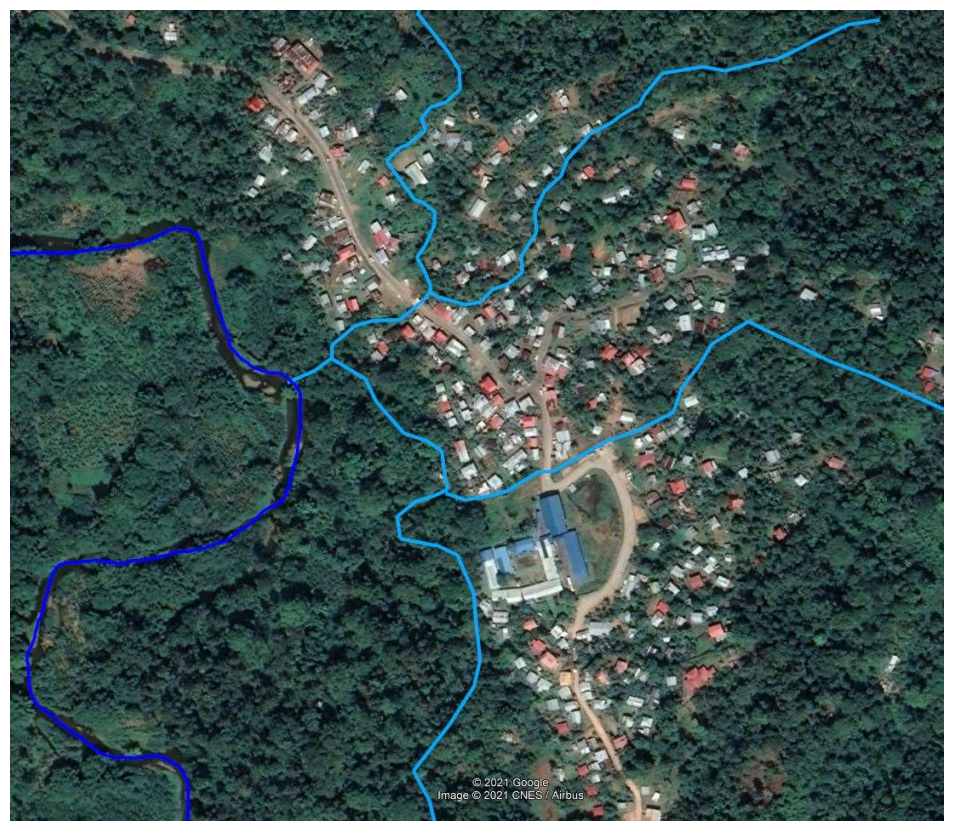

Figure 13. Creeks (light blue) go through central Valle Risco and connect to Rio Risco (dark blue). Image source: Google Maps. See Appendix A for full attribution and copyright licensing information.

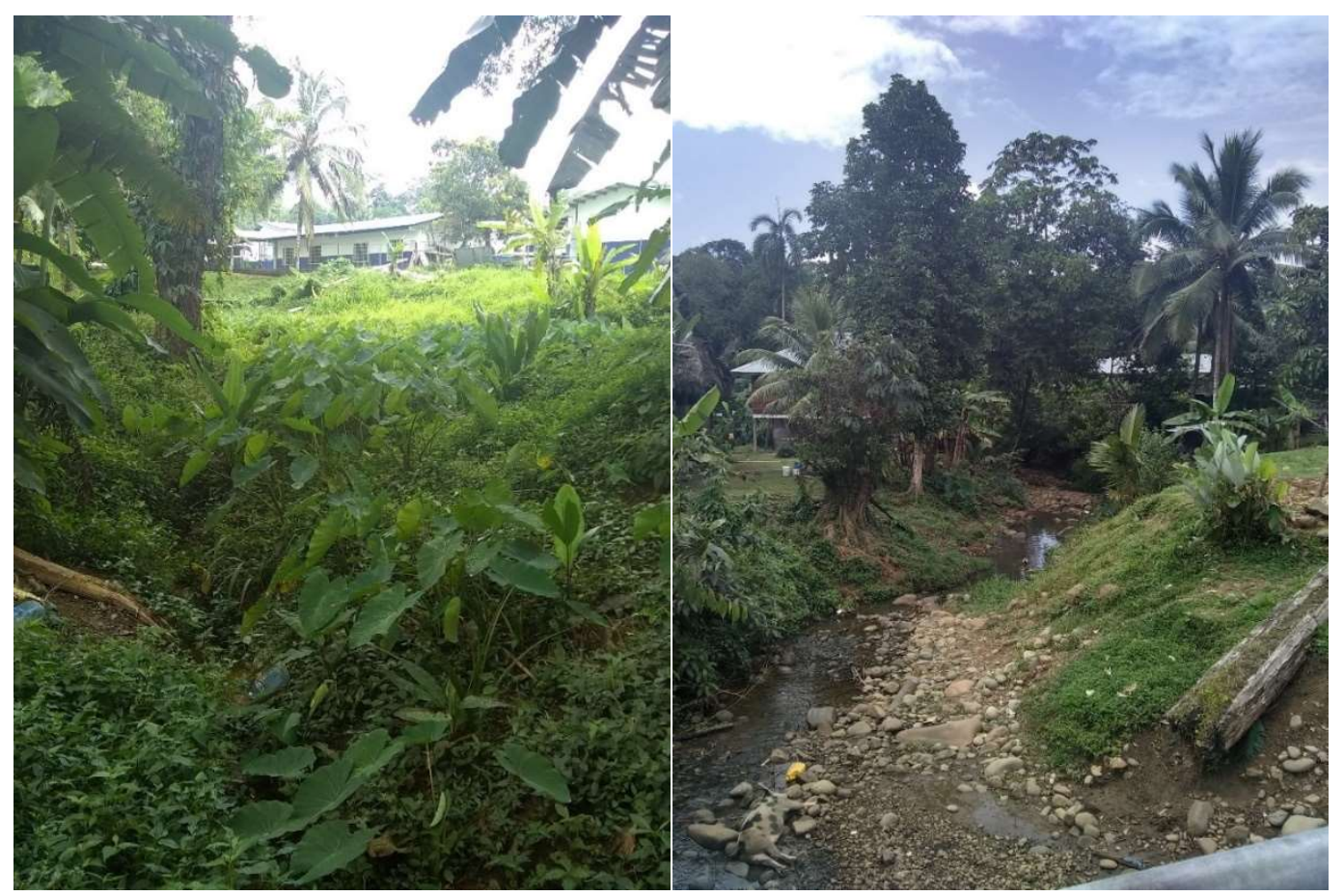

Figure 14. (Left) A ditch receiving runoff from the school. The edible plant taro grows in such ditches. Trash is visible. (Right) One of the main creeks which passes through town. Typical properties are seen in the riparian zone. Clear cutting causes increased runoff into the water. Also visible is a sleeping pig as well as some trash. Photos by author. 


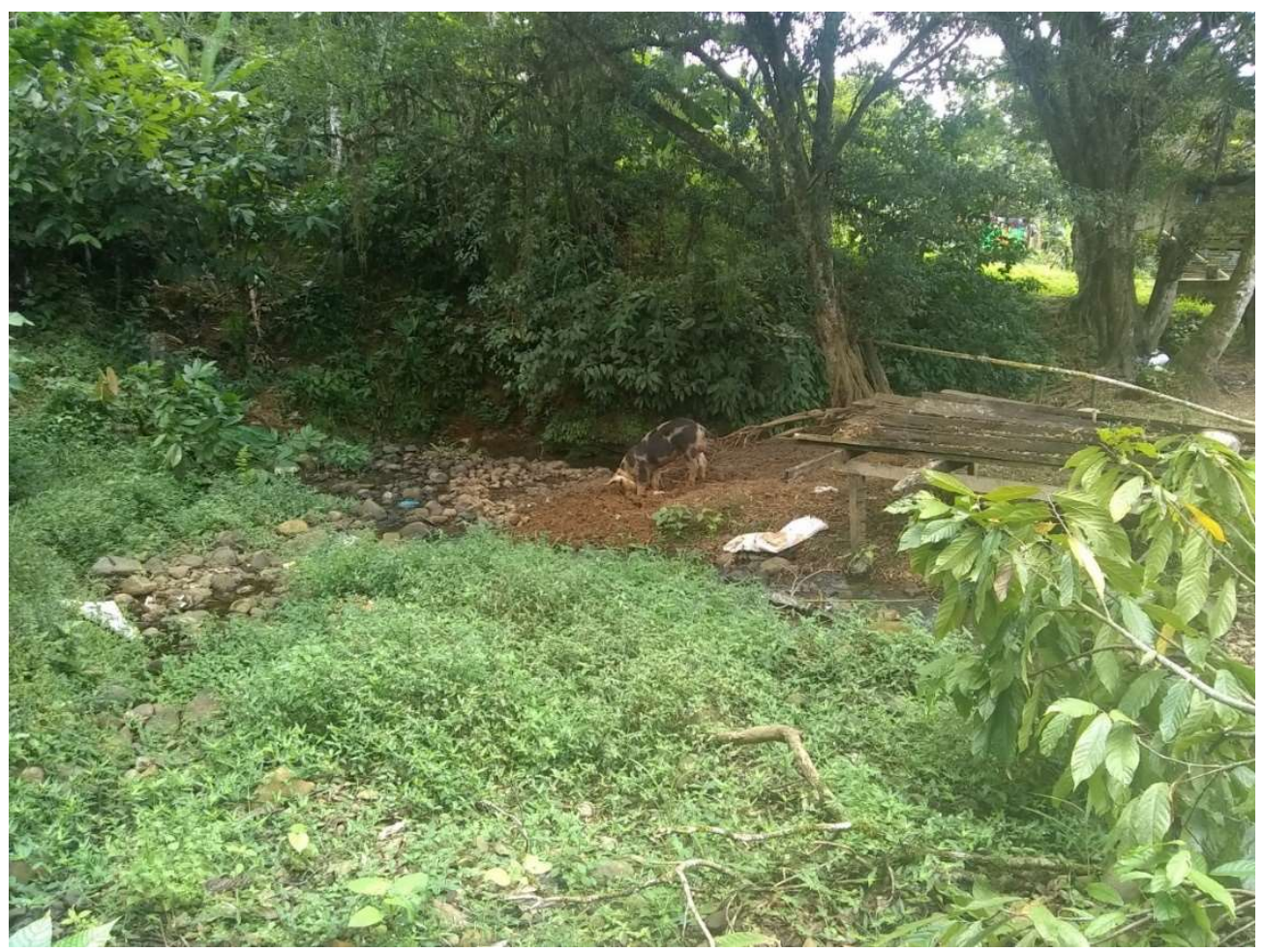

Figure 15. It is common practice to keep pigs tethered near creeks for easy access to water. Photo by author.

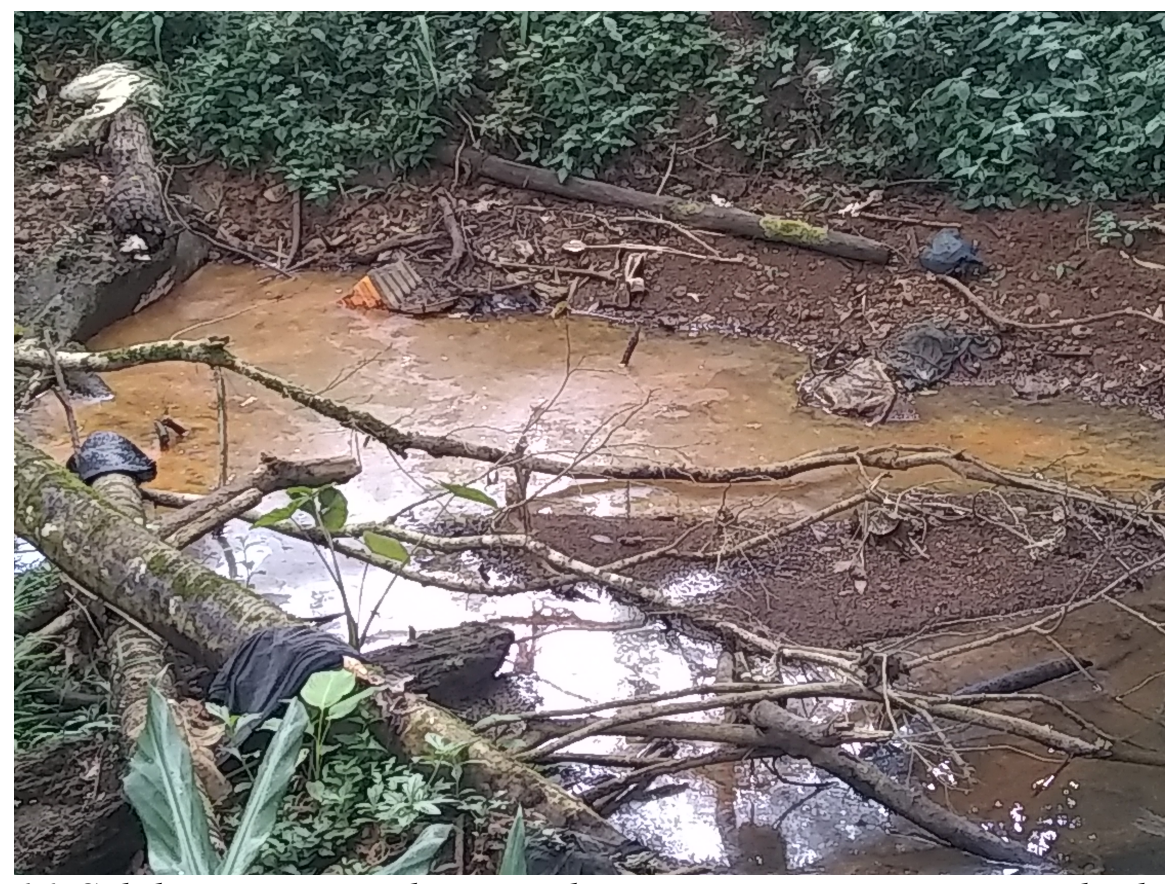

Figure 16. Solid waste accumulation and contamination in a main creek which runs behind houses and directly into Rio Risco. Photo by author 
A few of the main concerns brought about by improper drainage are as follows:

- Flooding

- Erosion

- Disease vectors

- Contamination of the river

Valle Risco is currently paving many of its roads and trails, and there are considerable issues with drainage around houses. As more of the town becomes built, there will be more impervious surface resulting in increased runoff, flooding, and pollution.

The creeks in Valle Risco drain an area of approximately 179 ha (Figure 17). Using rainfall data from the Smithsonian Tropical Research Institute (STRI) weather station (Smithsonian Tropical Research Institute 2021) located on the nearby Isla Colon off the coast from Almirante, design storms can be constructed for runoff estimation using the rational method following Dingman (2002; Table 4, Figure 18). As records were available for only a short period of time (19 years), the data were analyzed using the Generalized Extreme Value (GEV) distribution following Ilaboya and Otuaro (2019) and Hosking, Wallis, and Wood (1984; Appendix C). To account for the one-hour recording time interval, an adjustment factor was applied to the data following Young and McEnroe (2003; Appendix C). Land use runoff coefficients are taken from the Florida Department of Transportation (FDOT) for similar vegetation and soil type (clay) (Table 5) (FDOT January 2019). Time of concentration was calculated using the NRCS curve number:

$$
T_{c}=0.0526\left[\left(\frac{1000}{C N}\right)-9\right] L^{0.8} S^{-0.5}
$$

where $\mathrm{CN}$ is the NRCS curve number, $\mathrm{L}$ is the length of the longest path of water flow, and $\mathrm{S}$ is the average watershed slope. The NRCS equation is applicable in small rural watersheds (Salimi, et al. 2017). The soil in the region is generally dense red clay, so a curve number was chosen for NRCS soil type C (Natural Resources Conservation Service 2004). Calculation results are presented in Table 6 . This example considers a 20 -year storm following recommendations from the Council of Transportation Ministers of Central America (COMITRAN 2016). A 1-hour storm was considered as data were lacking for storms of longer durations. Following (Wurbs and James 2001), a 20-year, 1hour storm discharges $352 \mathrm{ft}^{3} / \mathrm{sec}$ through Valle Risco. 
Table 4. Intensity-duration-frequency (IDF) table for Isla Colon using data from STRI (Smithsonian Tropical Research Institute 2021). Hourly GEV rainfall data between 2002 and 2021. Data collected by STRI and processed by author.

\begin{tabular}{|c|cccccc|}
\hline \multicolumn{7}{|c|}{ Rainfall intensity (in/hr) } \\
\hline 2 \\
\hline 20 year & 2.37 & 1.65 & 1.36 & 1.00 & 0.62 & 0.40 \\
10 year & 1.88 & 1.33 & 1.12 & 0.81 & 0.51 & 0.33 \\
5 year & 1.52 & 1.11 & 0.93 & 0.66 & 0.42 & 0.28 \\
2 year & 1.19 & 0.89 & 0.74 & 0.49 & 0.31 & 0.20 \\
\hline
\end{tabular}

Table 5. Runoff coefficients from FDOT (January 2019)

\begin{tabular}{|c|ccc|}
\hline \multicolumn{4}{|c|}{ Runoff area and coefficients } \\
\hline Zone & C & area (ha) & percent \\
\hline Total watershed & 0.34 & 178.7 & 100 \\
Forest & 0.30 & 167.5 & 94 \\
Valle Risco & 0.90 & 11.14 & 6 \\
\hline
\end{tabular}

Table 6. Calculation using the NRCS curve number.

\begin{tabular}{|cc|}
\hline \multicolumn{2}{|c|}{ Time of concentration parameters } \\
\hline Tc $(\mathrm{min})$ & 79 \\
CN & 70 \\
L (ft) & 6345 \\
S (\%) & 15 \\
\hline
\end{tabular}




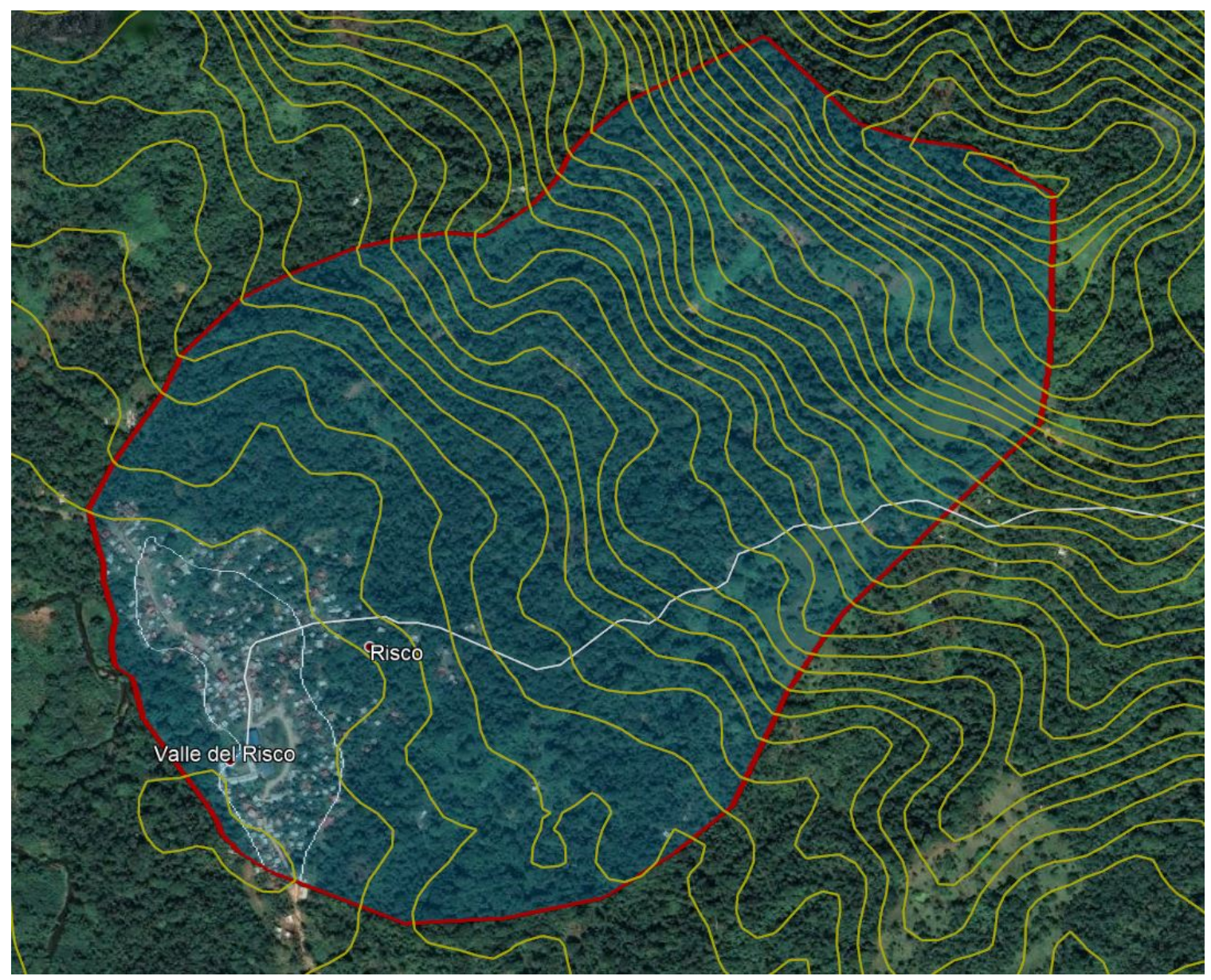

Figure 17. Estimated watershed of which Valle Risco is the mouth. Boundary estimated using Google Earth, an ESRI digital elevation model, and my memory of the region (ESRI 2020). The white border indicates different land use type for use in rational method calculation. $10 \mathrm{~m}$ contour lines are shown in yellow and were obtained using the System for Automated Geoscientific Analyses in QGIS. Image source: Google Maps. See Appendix A for full attribution and copyright licensing information. 


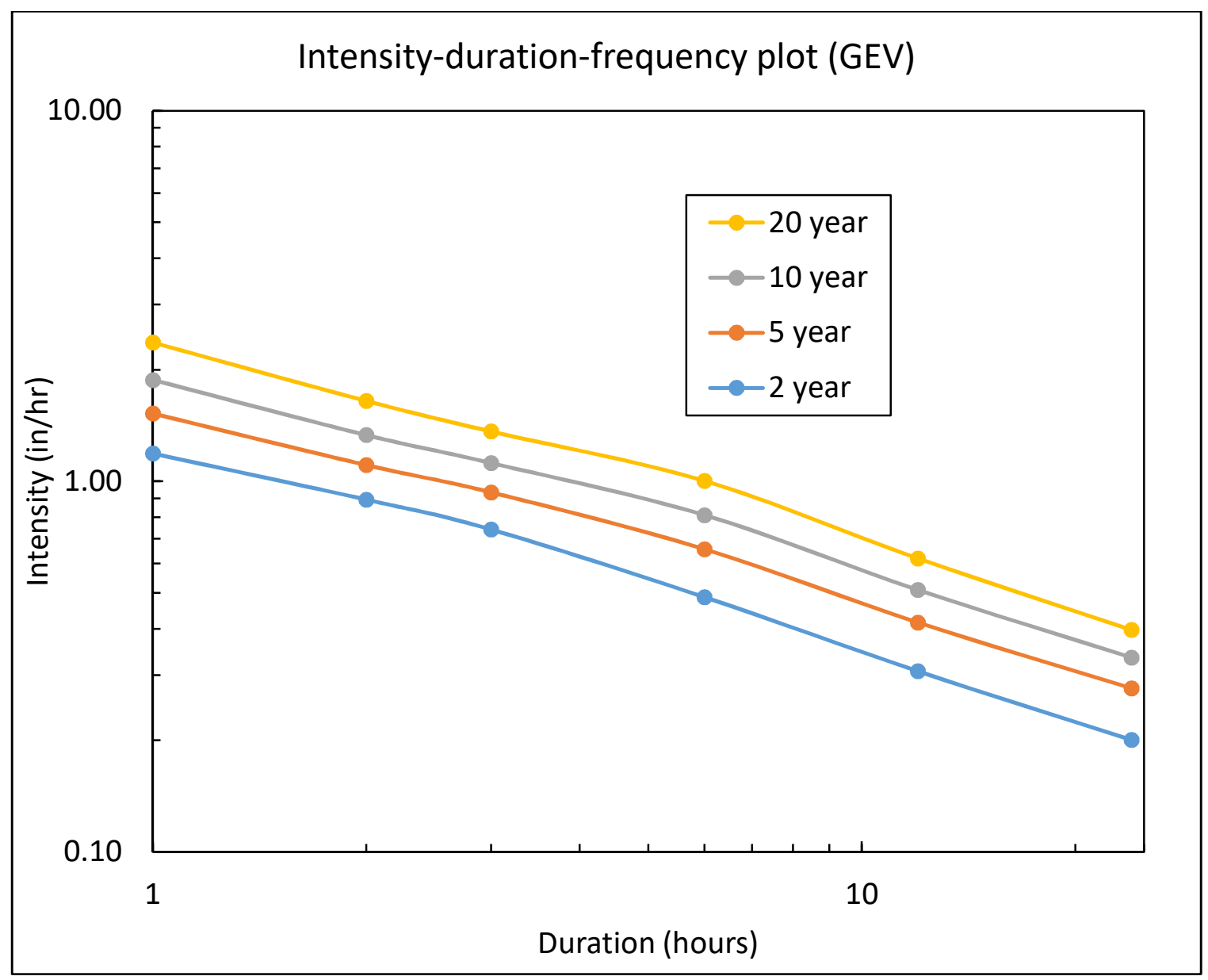

Figure 18. IDF curves for rainstorms in Bocas del Toro. Data from (Smithsonian Tropical Research Institute 2021).

The preceding discussion on storm events is used as a method of calculating the size needed for storm control measures. Commonly the time of concentration, or an approximation for the time taken for water to travel the longest path in the watershed, is used as a guideline for design parameters. The $352 \mathrm{ft}^{3} / \mathrm{sec}$ calculated is an approximation of the total amount of discharge through the outlet of the Valle Risco watershed as seen on the left side of Figure 17. Basic storm control measures are meant to mitigate flood problems by removing excess water from a given area, often by ditches or culverts. Not all of this flow will need to be accounted for in all storm water controls. Culverts like that shown in Figure 12 do not receive the complete flow of the Valle Risco watershed and would be designed for comparatively lower flow based on the area and time of concentration of the sub-watershed draining to them. Excess flow quantity is just one consideration for storm control measures.

In addition to removing excess water and discharging it into nearby water bodies, more recent design philosophy considers the effects of human activities on the quality of this excess water. As human areas are built they become increasingly impervious (e.g. roofs and roads). The means that not only is there greater water discharge, but this impervious 
surface contains the results of human activities. This can include oils from cars or other industrial activity, animal feces, and trash to name a few. Under conventional design these contaminants are carried directly and quickly to the nearest water body. As seen in Figure 17 the bulk of human activity in the watershed is at the outlet, meaning all the water flow in the watershed passes through the human built environment allowing it the chance to make contact with such contaminants. Low impact development (LID) approaches are a means of mitigating excessive storm water runoff while at the same time providing some basic treatment (Barkdoll and Watkins 2009). As Valle Risco is still largely unpaved, this is somewhat the de facto approach: residents dig ditches and perform basic stream routing. More developed areas built by government agencies have concrete ditches. Low impact development implementation could involve storm control measures such as bioswales and detention basins which allow for natural retention and infiltration to take place. These storm control measures attempt to combine the water control effects of routing excess water away from populated built areas while offering some treatment and natural infiltration.

However, certain LID approaches may be limited in their ability to handle heavier nutrient loads as well as mitigate certain inputs (Fanelli, Prestegaard and Palmer 2018). As such, inputs such as household greywater and runoff from livestock should be dealt with by other means. Household greywater comes from any human use that is not human waste, including bathing, laundry, and dish washing. Such water may have high concentrations of household products. Two potential solutions to household greywater include seepage pits, or holes dug into the ground at the water outlet from the home and filled with rock for water to percolate (Mihelcic, Fry, et al. 2009); and direct connection to a wastewater system. In the case of the second solution, a study of household water use should be undertaken and considered when designing the treatment process. Livestock are essentially a source of wastewater that cannot use the wastewater treatment system. Education programs addressing the dangers of allowing animals to defecate freely into surface waters may need to be implemented, as well as zoning and best management practices for livestock raising.

\subsection{Monitoring}

A critical aspect to environmental management is a monitoring plan. Management requires both an understanding of the desired condition as well as knowledge of the present condition. Continued monitoring can determine if given management activities have a desirable effect on the environment, and if other human activities have a positive or negative effect on desired outcomes. Water resources management involves the monitoring of water quantity and quality. This section also explores community-led science as a model for implementing monitoring activities.

Water quantity is the first part of water monitoring. Understanding how and in what volumes water flows over the local topography allows for planning regarding water use and consumption, land use planning, flood preparation, and water quality calculations (California Department of Water Resources 2020). Establishing a stream rating curve 
(relationship between stage and discharge) for the river and its tributaries would be a first step in understanding the flow of the river. This would require some technical knowledge, but could be learned quickly as there are standard methods (Dingman 2002).

The goal of water quality monitoring is, very broadly, determining if water is of sound nature for a specific goal or use. While, as has been discussed, a multi-stakeholder process informs the desired uses and thus goals for water quality, clear technical standards translate these into water quality parameters.

The simplest method of monitoring water is visual observation. This kind of observation could be used to assess factors such as turbidity and erosion. Using observations combined with local knowledge of land use could better inform where more precise and expensive sampling might be focused by identifying, for example, locations of recent land clearing, erosion, and industrial activity.

For a more precise technical understanding of the water's physical, chemical, and biological properties, sampling and field tests or laboratory analysis must be conducted. From my personal observation, and according to local agencies, there are no water quality testing laboratories available in the province of Bocas del Toro. The closest laboratories are about five hours away in the city of David, Chiriquí, where there is a Ministry of Health (MINSA) water quality office, as well as the Universidad Autonóma de Chiriquí. The MINSA lab offers testing for the parameters listed in Table 7.

Table 7. Parameters sampled by the Ministry of Health in David, Panama

\begin{tabular}{|l|l|}
\hline \multirow{4}{*}{ Physical } & Physical \\
\cline { 2 - 2 } & Turbidity \\
\cline { 2 - 2 } & Conductivity \\
\cline { 2 - 2 } & Total Dissolved Solids \\
\cline { 2 - 2 } & Temperature \\
\hline \multirow{4}{*}{ Chemical } & Nitrate \\
\cline { 2 - 2 } & Nitrite \\
\cline { 2 - 2 } & Iron \\
\cline { 2 - 2 } & Sulfate \\
\hline \multirow{4}{*}{ Biological } & Coliforms \\
\cline { 2 - 2 } & E. Coli \\
\hline
\end{tabular}

Samples must be chilled to $4^{\circ} \mathrm{C}$ and taken to the lab within 24 hours of collection. Furthermore, in the reports from the Panamanian government, it is part of the national plans for water security to increase monitoring of surface water quality of the parameters in Table 3 in a citizen participatory framework. The University lab can test for those 
parameters as well as $\mathrm{BOD}_{5}$; however, samples must reach the lab within 4 hours of collection, making viability of samples from Valle Risco impossible.

While I was working in the area, I reached out to the head of testing at the MINSA laboratory. The head of testing told me that sampling would be provided for free for Peace Corps Volunteers; however, it is uncertain if this offer would hold for Panamanian citizens. Assuming this offer holds, this would be a financially viable sampling method as costs would be just the cost of transportation. An initial sampling program could be very thorough and include sampling of all tributary creeks as well as along the main channel at key points such as before and after towns. This initial sampling would give a detailed initial look at water quality with respect to location, and provide a baseline for goals to be set.

An alternative or complement to laboratory analysis is biomonitoring. Biomonitoring is, as its name implies, the monitoring of environmental quality by observing characteristics of biological systems. While biomonitoring may have been in practice in some form dating to prehistory, it was recently formalized in the 1970s to incorporate into modern western science for the application to monitoring surface water quality (Hawkes 1997). While various kinds of organisms can be used for biomonitoring, the most common are macroinvertebrate communities. These are a preferred group as they respond to a number of environmental conditions, exist in many different areas with a high variety of species, and are relatively sedentary (Mandaville 2002).

The basic concept of biomonitoring relies on the niche theory of biology, which is that different organisms will fit in to a niche of survival. Given the proper environmental conditions, several niches will be filled. These environmental conditions are determined by how sensitive a species is to a number of parameters (e.g., temperature, TSS, DO, and $\mathrm{pH})$. For streams in a given geographical region, a standard is set for the varieties of given species, or species richness. This can then be used to compare other streams surrounded by different land uses. This species richness thus becomes a metric to assess stream environmental health using direct biological observation. There are a variety of methods to collect and analyze samples, ranging from more labor-intensive to quick and easy methods (Mandaville 2002). Regardless of which method is used, it is advisable to have consultation with trained experts in identification at least for preliminary stages as well as for quality control.

The use of benthic macroinvertebrates as a measure of stream quality is well researched in temperate zones. Their use in tropical areas has not been researched as long; however, there are an increasing number of bodies of research, especially in Costa Rica which shares a border with Bocas del Toro (Sedeno-Diaz, Kohlmnan and Lopez-Lopez 2012, Kohlmann, Mitsch and Hansen 2008, Stein, Springer and Kohlmann 2008, Helson and Williams 2013, Martins, et al. 2020, Fenoglio, Badino and Bona 2002, Gutierrez-Fonseca and Lorion 2014, Springer 2009). In Helson and Williams (2013), a multimetric index was developed for the Panama Canal watershed. This wealth of literature indicates that reference material as well as professionals knowledgeable to the area's biology are present and may provide a starting point for development of more locally applicable 
metrics. However, because of this lack of documentation of local environmental conditions, establishing metrics for the Valle Risco watershed would be a significant undertaking, but not impossible.

Monitoring is the process of collecting and constructing knowledge and analyzing it. Monitoring provides knowledge of systems which directly affect the livelihoods of the residents of Valle Risco. For consistency in results and just allocation of power, this process of knowledge formation should be led by the community. Furthermore, as stated, the province has a lack of administrative resources to devote to monitoring every subwatershed, and the plans and documents compiled by Panama advocate community watershed management as a means to alleviate this.

Citizen science (CS) is an approach to science in which the public are involved in various steps of science including question forming, experimental design, data collection, and data interpretation. Such endeavors have been used in biology, wildlife management, astronomy, and most pertinent to this report, water resources management. Public education, understanding, and involvement are stated potential benefits of CS (Crall, Jordan, et al. 2012). Similar approaches have been applied to rural areas where governments do not have the resources to implement direct data collection for water resource work (Liu, et al. 2008).

CS is an approach that may help guide the management process in Valle Risco. Generally, science benefits from a variety of different perspectives collaborating in problem solving and inquiry. TEK and local knowledge may help fill in gaps of knowledge as well as provide insight in design (Gomani, et al. 2010, Guillemette, et al. 2017). Some challenges, however, exist for implementation. Data quality depends on the skill level and consistency of the volunteers (Crall, Newman, et al. 2011, Riesch and Potter 2014). Some CS projects have noted that some data, such as species identification, suffer more uncertainty and error than others, such as the use of GPS mapping or rain gauge reading (Crall, Newman, et al. 2011). Researchers recommend the proper collaborative design of data collection which would minimize these errors (Crall, Newman, et al. 2011). Another challenge in these programs is the nature of the volunteers themselves. These initiatives require an understanding of what motivates volunteers, what allows them to participate, and what keeps them involved. Some projects found that participation was not equitable among all members of society (Shinbrot, et al. 2020, Land-Zandstra, et al. 2016, Brossard, Lewenstein and Bonney 2005, Hobbs and White 2012). Often times, people who were older, educated, and financially well off were the most likely to participate in CS projects (Shinbrot, et al. 2020). For groups that did have demographic diversity, motivations varied among various groups. Some participants were motivated mostly by curiosity and education, while others were motivated by socialization or a chance to connect with nature (Hobbs and White 2012). Retention of volunteers and their enthusiasm for work has proven a challenge for very long-term projects (Deutsch and Ruiz-Cordova 2015). Some recommendations include providing adequate support and attention to volunteers, high-quality and regular training, and assistance from outside organizations and institutions (Deutsch and Ruiz-Cordova 2015). 
It is noted that many of these studies pertained to western groups, and that motivations and strategies may vary according to population. This further stresses why leadership and decision making should be located within the community itself, where people are more likely to understand the nuances of what motivates people. Another means of ensuring regular, high-quality, long-term monitoring would be to pay a dedicated data collector. Moriarty, et al. (2013) found that for the implementation of community-led infrastructure projects, burnout and resentment were common for volunteer organizations, and thus they recommended the professionalization of the field. CS presents a viable communityoriented approach to data collection that, while promising, presents a number of challenges to be overcome. Experimental design and project logistics must be tailored to the applicability of the methods.

\subsection{Ecosystem Services}

Ecosystem services are generally a framework of valuation of ecosystems according to various human needs as served by the ecosystem. Meynard et al. (2007) describe four different levels at which this occurs: direct resources such as lumber, water, or fire wood; regulation of environmental variables such as climate, environmental health, and water quality; cultural resources of aesthetics and spiritual importance; and biogeochemical cycles such as soil formation. The concept of ecosystem services is a policy-making tool that helps decision makers prioritize and negotiate conservation efforts. Balvanera et al (2012) describe five different ways in which ecosystem services are preserved in policy making. These include the generation of knowledge, the intervention of institutions and governments, the use social norms, the implementation of technologies, and the use market and finance tools.

Watersheds and their associated processes provide vital resources which meet many community needs. Any complete and meaningful assessment of ecosystem services in the Rio Risco watershed would need to be compiled by the people who live from that land. The following are some examples of the possible uses in each category. Direct water resources include the water itself for drinking, cooking, and washing, fish consumption, material resource transportation, and crop irrigation. Direct watershed ecosystem resources include construction timber, firewood, and edible and medicinal flora and fauna. Some regulatory resources include managing river flooding with a healthy riparian zone, ensuring consistent water supply with a healthy surrounding forest ecosystem, and climate regulation from the forest flora. Cultural resources include the knowledge and lore of the uses of plants, and the sense of self and place from living in and working the land. Finally, biogeochemical services from the watershed include soil and water quality.

Problem solving in natural resources management requires a knowledge of the given ecosystem. Knowledge generation is a continual process and is dependent on the actor performing it. The incorporation of citizen and community science for management decision making, as discussed previously, is one example of knowledge generation. This kind of involvement is a means of not only monitoring the ecosystem for decisions on conservation practice, but establishes local stakeholders as lead decision makers and 
fosters ownership of ecosystem service knowledge. Meynard et al. (2007) describes the implementation of ecosystem services for decision making in rural communities in Chile. Their research found that ecosystem services acted as a means of fostering communication between local stakeholders, scientists, policy makers, institutions, and other decision making participants. The research involved a series of educational and brainstorming workshops with local communities to learn about watershed ecosystems, ecosystem services, and discuss needs and aspirations of communities. Workshops were tailored to various age groups including high school students, adults, and elders (Meynard, et al. 2007). Floress et. al. (2015) describes an "ongoing learning and problemsolving process" of collaborative watershed management. While traditional ecological knowledge (TEK) is discussed in greater detail elsewhere in this report, it is important to consider the role of indigenous and local knowledges and methods of constructing knowledge to inform decision making. Ellis (2005) discusses the role TEK is able to take in ecological decision making in Canada. Western sciences is generally the privileged method of knowledge generation over traditional lore. This creates barriers for those without access to western education and resources. It further acts to eliminate indigenous culture by hindering its preservation as a meaningful means of making decisions. Funding is most often allocated to western science endeavors, and when TEK is incorporated into management schemes, it is often only when validated by western scientific methods and appropriated by western scientific institutions (Ellis 2005). Strengthening of local knowledge involves privileging and funding TEK. This means considering such knowledge when decisions are being made.

Managing ecosystems and natural resources from multiple levels of government has been well studied and is a continuously developing field. As stated previously in this report, the Panamanian government has expressed the goal of conserving the integrity of water systems in the country. Panama has an interest in maintaining water flow in the Changuinola River as it supplies hydropower and irrigates fields generating food and wealth. Furthermore, monitoring flow allows for planning for flood conditions. It is in the interest of the Panamanian government to assist and empower communities in the upper watersheds to maintain their resources. Another way that Panama has already engaged in management is the formation of the protected area. This has sparked controversy in land use sovereignty in the region. Some concerns are that enforcing a protected area means that the rural poor are unable to use the natural resources at their disposal to earn income. Ferraro et al (2010) discusses the cases in which protected areas do not impede exit from poverty. These cases, in general, require good strength of local organizations (Ferraro, Hanauer and Sims 2010). Meynard et. al. (2007) supports this by the observation that communities which saw the greatest success in education and implementation of natural resource policy implementation were those which already had strong local institutions. The cooperation of the national government and international organizations is very helpful in the success of plans as they can implement larger scale logistics as well as distribute more resources. Involvement of the national government, however, comes with its own associated risk. Floress et al (2015) cautions that careful consideration be given for collaboration between different levels of government, and that unless governments are 
willing to relinquish power, collaboration may further centralize power and exacerbate inequalities (Floress, et al. 2015).

Social norms can be a means of establishing consistent participation of entire communities in conservation efforts (Chen, et al. 2008). Community science is one potential means of encouraging participation in conservation and may be useful in building a community mindset of environment. Educational and cultural events may also be used to promote conservation activities and foster intentionality in the connection to nature. Education may involve workshops focusing on peoples' use of water in their daily lives, as well as other benefits they receive from healthy stream ecosystems.

Determining the uses people have for water helps define what is meant by water quality. A clear understanding of desired water quality parameters is used to set treatment goals. Technology can then be used to achieve goals. An example is the U.S. EPA's water quality based effluent limits. In this framework, streams are evaluated for their baseline water quality and their desired uses in society. These are then used to determine acceptable water quality standards for any given reach. These water quality parameters are used to calculate acceptable treatment standards for upstream entities which may discharge waters to the stream (USEPA 2010). While there are no users along Rio Risco that may be considered point source dischargers, a similar framework may be helpful in communicating and encouraging the use of best management practices.

A more commonly discussed method of implementing ecosystems services is the use of market and financial tools. Payment for ecosystem services is where a large financial entity pays landowners for not developing the land or managing land in ways that might otherwise earn them income. For example, the Panama Canal Authority has explored paying landowners in the watershed not to use the land to raise cattle, an activity which would earn them great income, and instead to let the land remain forested, which ensures consistent water supply for the Panama Canal (Acamowicz, et al. 2019). It may be unlikely that any large financial entity would target Rio Risco for conservation in the near term; however, the model may be an effective means of communicating the benefits of conservation. Attaching a dollar value to benefits earned from potentially costly conservation measures may make more tangible the abstract concepts of ecology (Figure 19). Such benefits may include reduced infrastructure damage from unmitigated storm water, and healthcare savings from reduced disease caused by poorly treated water or disease vectors. 


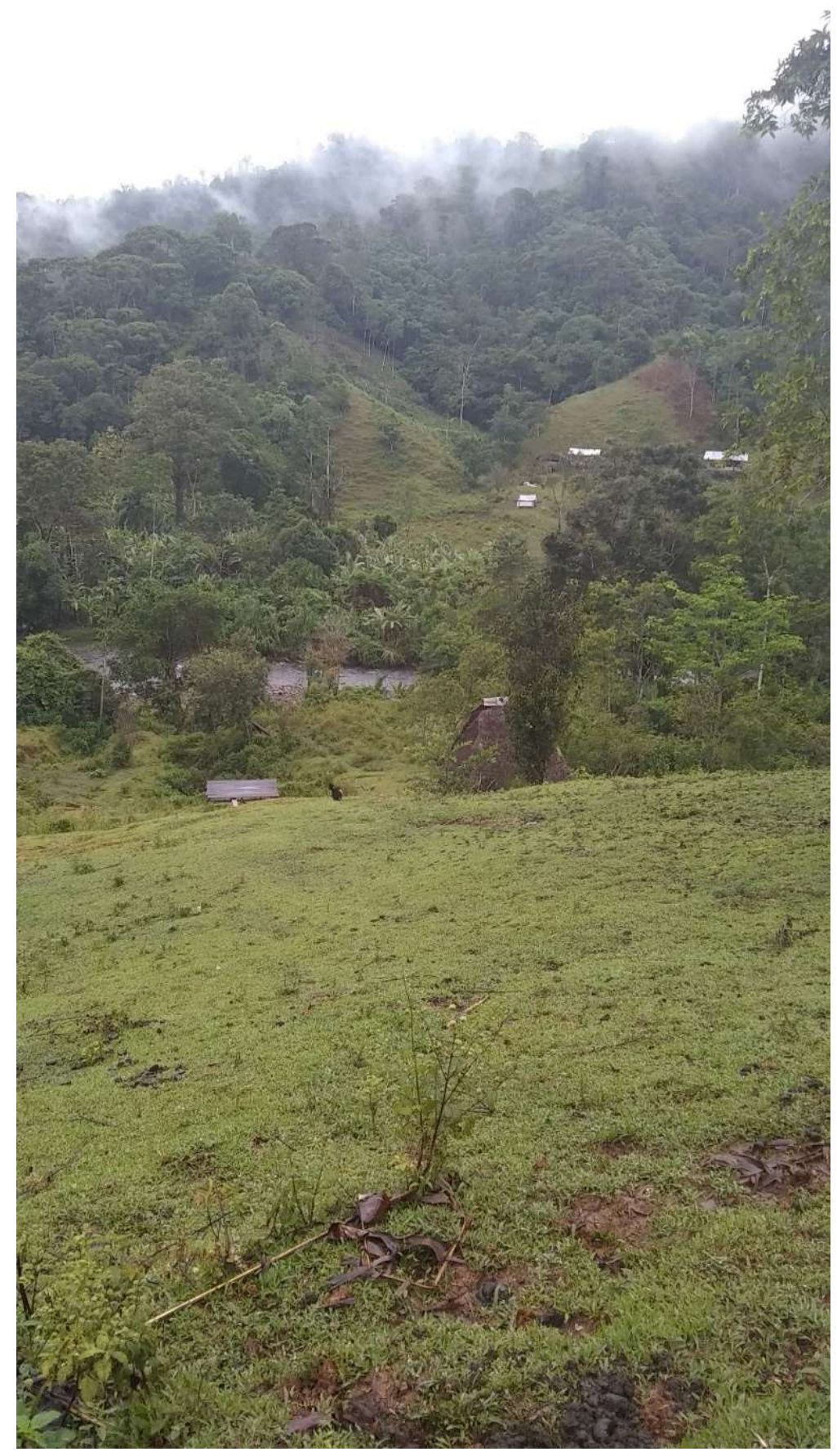

Figure 19. An upstream reach of Rio Risco is surrounded by much pasture land. Cows are an important source of revenue for the locals. An ES model may be useful in discussing appropriate uses of upstream land. (Photo by author) 


\section{Recommendations}

Based on the preceding discussion are the following recommendations for implementation of a watershed management plan in Valle Risco.

1. Form a watershed committee

As discussed, power must be located in the community of Valle Risco. One possible way to implement this is the formation of a water committee which is responsible for ensuring environmental sustainability of development projects. Caution must be taken as committees can be another method of consolidating power within the community. Democratic and transparent processes should be advocated for. The equitable distribution of power would also require the acknowledgement of several modes of knowledge generation.

2. Strongly consider wastewater solution alternatives

As the population and population density of Valle Risco increase, wastewater will become more and more important in considering the health of the community. However, as noted, the region presents some challenges to the technology implemented. This report has explored implementing facultative lagoons and constructed wetlands as well as clustered septic tanks. The main considerations for what to implement include the cost versus effectiveness and lifetime of the technology, as well as implementation issues (construction, operations, and maintenance) in a densely populated area with steep topography.

3. Address storm water and drainage sustainability as larger areas are paved and developed

As more of Valle Risco becomes built and impervious, the heavy rainfall will cause issues related to water quality and quantity. A proactive approach to developing and maintaining storm water systems is needed as other infrastructure is built. An LID approach offers benefits of both controlling excess quantity while providing some water quality improvement. Education programs should be developed and implemented regarding the management of livestock as is related to water quality. Finally, consideration should be taken for household greywater either to be mitigated onsite with seepage pits or else incorporated into a larger wastewater system.

\section{Set up regular monitoring of water quality}

If possible, coordinating with MINSA would allow quantified measurements of various water quality parameters. Samples would ideally be taken at various key points of various reaches of creeks entering Rio Risco, as well as Rio Risco itself. Some issues that arise with this implementation are economic viability of collecting samples, managing records, and translating results into land management decisions. It is also uncertain if MINSA will 
have the capacity to continuously carry out this lab sampling, and thus, while it would be more costly, a partnership with the university may be preferred.

Biomonitoring offers a low-tech yet effective means of understanding the health of the river. An initial barrier exists in the technical knowledge required in identifying species and establishing a stream quality metric. These barriers could be confronted through a partnership with a university or other organization. Likewise, species identification could be aided by local knowledge of flora and fauna.

At the most basic level, records could be kept of basic water quality factors from simple observation. This might indicate things such as turbidity and discoloration, quantity, flow, and debris.

\section{Use an ecosystem services approach to planning}

An ecosystems approach may offer an effective means of involving multiple stakeholders in the planning process. It encompasses a wide variety of frameworks for fostering communication and negotiation of ecosystem uses and may be a helpful method of establishing goals and appropriate technology. 


\section{Conclusions}

The preceding has been a discussion on considerations for the implementation of a multistakeholder watershed management plan in Valle Risco. Recommendations were made with respect to wastewater management, storm water drainage, water quality monitoring activities, and the use of ecosystem services a planning tool. Further considerations included aspects of social issues and potential collaboration with other organizations.

As this is a conservation effort which involves the state, there are inevitably concerns of power and rights at play. Groups that are historically and currently targeted and marginalized face the risk of losing more power to entities such as the state or corporations. This is the delicate nature of multi-stakeholder initiatives. The powerful may consolidate more power. Likewise, paradigms for constructing knowledge and determining goals will vary between groups. For efforts to be truly equitable and just, power must be in the hands of indigenous people. This is a requirement that governments and corporations may not be willing to concede.

As wastewater solutions are increasingly required for the area as it grows, leaders should consider startup, operations and maintenance, and growth costs, as well as access to space required for treatment technologies. As the area experiences high rainfall, drainage will be a concern as more of the town becomes impervious. LID is a kind of technology which combines the benefits of increased stormwater capacity with some preliminary treatment. Monitoring is an important part of watershed management as it helps set goals and assess conservation efforts. Community science is a means of gathering information which acknowledges local leadership and places importance on indigenous forms of knowing. Finally, the ecosystem services model is a framework for analysis and decision making that incorporates the needs and thoughts of several different stakeholders.

These considerations have been used to provide very broad recommendations, as decision making must ultimately be in the hands of the community. A committee or other decision making body could assist in keeping power in the hands of the community, as well as ensuring effective coordination and accountability for management work. Wastewater solutions such as lagoons or constructed wetlands may offer lower cost and more manageable solutions for the growing population. Low impact storm water management could be effective at mitigating heavy storms as well as providing some protection of water quality in Rio Risco.

As of March 2020, progress was already being made in organizing community drinking water committees, and the town of Valle Risco had just elected its development committee. There is no doubt that the development committee is continuing its work in planning the future growth of Valle Risco. As a resource for the community, a summary of this work will be translated and shared with community members seeking to achieve growth in an environmentally mindful manner.

A key takeaway of this work is that any endeavor to manage the environment absolutely must include the voices of indigenous locals in leadership. There is a history of 
colonizers and governments marginalizing indigenous people, even in the name of environmental conservation. Furthermore, indigenous leadership prioritizes goals, knowledge, and forms of knowledge generation that are vital for understanding environments and their conservation. 


\section{References}

Acamowicz, Wiktor, Laura Calderon-Etter, Alicia Entem, Eli P. Fenichel, Jefferson S. Hall, Patrick Lloyd-Smith, Fred L. Ogden, Jason A. Regina, Mani Rouhi Rad, and Robert F. Stallard. 2019. "Assessing ecological infrastructure investments." PNAS 5254-5261.

Adler, Peter S., and Juliana E. Birkhoff. n.d. Building Trust: When Knowledge from "Here" Meets Knowledge From "Away. Portland, OR: The National Policy Consensus Center.

Apgar, Marina J., Will Allen, Kevin Moore, and James Ataria. 2015. "Understanding adaptation and transformation through indigenous practice: the case of the Guna of Panama." Ecology and Society.

Autoridad Nacional del Ambiente. June 2014. "GEO Panama 2014 Informe del Estado del Ambiente." Panama City, Panama.

Autoridad Nacional del Ambiente. 2011. "Plan Nacional de Gestión Integrada de Recursos Hídricos de la República de Panamá 2010-2030." Panama City, Panama.

Balvanera, Patricia, Maria Uriarte, Lucia Almiedo-Leñero, Alice Altesor, Fabrice DeClerck, Toby Gardner, Jefferson Hall, et al. 2012. "Ecosystem services research in Latin America: The state of the art." Ecosystem Services 56-70.

Barkdoll, Brian D., and David W. Watkins, . 2009. Stormwater Management Conventional and Low Impact Methods. Deer Park, NY: Linus Publications, Inc.

Brossard, Dominique, Bruce Lewenstein, and Rick Bonney. 2005. "Scientific knowledge and attitude change: The impact of a citizen science project." International Journal of Science Education 1099-1121.

California Department of Water Resources. 2020. Handbook for Water Budget Development With or Without Models. Sacramento, CA: California Department of Water Resources.

Chen, Xiadong, Frank Lupi, Guangming He, and Jianguo Liu. 2008. "Linking social norms to efficient conservation investment in payments for ecosystem services." PNAS 11812-11817.

Comité de Alto Nivel de Seguridad Hídrica. 2016. "Plan Nacional de Seguridad Hídrica 2015-2050: Agua para Todos." Panamá, República de Panamá.

COMITRAN. 2016. Hidrologic and Hydraulic Technical Considerations Manual for Road Infrastructure in Central America (1st ed.). El Salvador, C.A.: Ministry of Public Works, Transportation, Housing, and Urban Development. 
Crall, Alycia W., Gregory J. Newman, Thomas J. Stohlgren, Kristin A. Holfelder, Jim Graham, and Donald M. Waller. 2011. "Assessing citizen science data quality: an invasive species case study." Conservation Letters 433-442.

Crall, Alycia W., Rebecca Jordan, Kristin Holfelder, Gregory J. Newman, Jim Graham, and Donald M. Waller. 2012. "The impacts of an invasive species citizen science training program on participant attitudes, behavior, and science literacy." Public Understanding of Science 745-764.

Davies, Jocelyn, Rosemary Hill, Fiona J. Walsh, Marcus Sandford, Dermot Smyth, and Miles C. Holmes. 2013. "Innovation in Management Plans for Community Conserved Areas: Experiences from Australian Indigenous Protected Areas." Ecology and Society.

Deutsch, William G., and Sergio S. Ruiz-Cordova. 2015. "Trends, challenges, and responses of a 20 -year, volunteer water monitoring program in Alabama." Ecology \& Society.

Dingman, S. Lawrence. 2002. Physical Hydrology. Long Grove, IL: Waveland Press, Inc.

Ellis, Stephen C. 2005. "Meaningful Consideration? A Review of Traditional Knowledge in Environmental Decision Making." Arctic 66-77.

ESRI. 2020. ArcGIS Hub. 11 17. Accessed 12021. https://hub.arcgis.com/datasets/4ad7604171df447988008a2e3690a375.

Fanelli, Rosemary M., Karen L. Prestegaard, and Margaret A. Palmer. 2018. "Urban Legacies: Aquatic stressors and low aquatic biodiversity persist despite implementation of regenerative stormwater conveyance systems." Freshwater Science 818-833.

FDOT. January 2019. Office of Design, Drainage Section. Tallahassee, Florida: State of Florida Department of Transportation.

Fenoglio, Stefano, Guido Badino, and Francesca Bona. 2002. "Benthic macroinvertebrate communities as indicators of river environment quality: an experience in Nicaragua." Revista de Biologia Tropical 1125-1131.

Ferraro, Paul J., Merlin M. Hanauer, and Katherine R. E. Sims. 2010. "Conditions associated with protected area success in conservation and poverty reduction." PNAS 13913-13918.

Finley-Brook, Mary, and Curtis Thomas. 2010. "Treatment of Displaced Indigenous Populations in Two Large Hydro Projects in Panama." Water Alternatives 269290. 
Floress, Kristin, Kofi Akamani, Kathleen E. Halvorsen, Andrew T. Kozich, and Mae Davenport. 2015. "The Role of Social Science in Successfully Implementing Watershed Management Strategies." Journal of Contemporary Water Research \& Education 85-105.

Gomani, M.C., O. Dietrich, G. Lischeid, H. Mahoo, F. Mahay, B. Mbilinyi, and J. Sarmett. 2010. "Establishment of a hydrological monitoring network in a tropical African catchment: An integrated participatory approach." Physics and Chemistry of the Earth 648-656.

Guillemette, Mathieu, Catherine Potvin, Lauliano Martinez, Bonarge Pacheco, Dioniz Ca no, and Ignacio Perez. 2017. "Building a common description of land cover in a tropical watershed plagued with intercultural conflicts: The value of participatory 3D modelling." Facets 2: 195-211.

Gutierrez-Fonseca, Pablo E., and Christopher M. Lorion. 2014. "Application of the BMWP-Costa Rica biotic index in aquatic biomonitoring: sensitivity to collection method and sampling intensity." Revista de Biologia Tropical 275-289.

Hawkes, H. A. 1997. "Origin and development of the biological monitoring working party score system." Water Resources 964-968.

Helson, Julie E., and D. Dudley Williams. 2013. "Development of a macroinvertebrate multimetric index for the assessment of low-land streams in the neotropics." Ecological Indicators 167-178.

Hetherington, Kregg, and Jeremy M. Campbell. 2014. "Nature, Infrastructure, and the State: Rethinking Development in Latin America." The Journal of Latin American and Caribbean Anthropology 191-194.

Hill, Rosemary, Chrissy Grant, Melissa George, Catherine J. Robinson, Sue Jackson, and Nick Abel. 2012. "A Typology of Indigenous Engagement in Australian Environmental Management: Implications for Knowledge Integration and Social Ecological System Sustainability." Ecology and Society.

Hobbs, Sarah J., and Piran C.L. White. 2012. "Motivations and barriers in relation to community participation in biodiversity recording." Journal for Nature Conservation 364-373.

Hoegh-Guldberg, O., D. Jacob, M. Taylor, M. Bindi, S. Brown, I. Camilloni, A. Diedhiou, et al. 2018. 2018: Impacts of $1.5^{\circ} \mathrm{C}$ Global Warming on Natural and Human Systems. In: Global Warming of $1.5^{\circ} \mathrm{C}$. An IPCC Special Report on the impacts of global warming of $1.5^{\circ} \mathrm{C}$ above pre-industrial levels and related global greenhouse gas emission pathways, in the conte. IPCC.

Hosking, J.R.M., J.R. Wallis, and E.F. Wood. 1984. Estimation of the Generalized Extreme-Value Distribution by the Method of Probability Weighted Moments. 
Technical Summary Report, Madison: University of Wisconsin-Madison Mathematics Research Center.

Ilaboya, Idowu Rudolph, and Ebierin Akpoebidimiyen Otuaro. 2019. "Simple to Use Microsoft Excel Template for Estimating the Parameters of Some Selected Probability Distribution Model by Method of L-Moment." Civil and Environmental Research 43-56.

Jordan-Ramos, Osvaldo. 2010. Indigenous Mobilization, Institutionalization and Resistance: The Ngobe Movement for Political Autonomy in Western Panama. Dissertation, Gainesville, FL: University of Florida.

Keraita, Bernard, Pay Drechsel, and Philip Amoah. 2003. "Influence of urban wastewater on stream water quality and agriculture in and around Kumasi, Ghana." Urban Wastewater and Agriculture 171-178.

Kohlmann, Bert, William J. Mitsch, and David O. Hansen. 2008. "Ecological management and sustainable development in the humid tropics of Costa Rica." Ecological Engineering 254-266.

Land-Zandstra, Anne, Jeroen L. A. Devilee, Frans Snik, Franka Buurmeijer, and Jos M. van den Broek. 2016. "Citizen science on a smartphone: Participants' motivations and learning." Public Understanding of Science 45-60.

Larkin, Brian. 2013. "The Politics and Poetics of Infrastructure." Annual Review of Anthropology 327-343.

Liu, Benjamin M., Yitayew Abebe, Oloro V. McHugh, Amy S. Collick, Brhane Gebrekidan, and Tammo S. Steenhuis. 2008. "Overcoming limited information through participatory watershed management: Case study in Amhara, Ethiopia." Physics and Chemistry of the Earth 13-21.

Maddox, Perry. 2017. A Politics of Means: Farming, Organizing, and Living Along a Late Liberal Seam. Master's Thesis, Montréal: McGill University.

Mandaville, S. M. 2002. Benthic Macroinvertebrates in Freshwaters-Taxa Tolerance Values, Metrics, and Protocols. Halifax: Soil \& Water Conservation Society of Metro Halifax.

Marchezini, Victor. 2015. "The Biopolitics of Disaster: Power, Discourses, and Practices." Human Organization 362-371.

Martins, Isabela, Diego Rodrigues Macedo, Robert M. Hughes, and Marcos Callisto. 2020. "Are multiple multimetric indices effective for assessing ecological condition in tropical basins?" Ecological Indicators. 
Metcalf \& Eddy Inc, George Tchobanoglous, H. David Stensel, Ryujiro Tsuchihashi, and Franklin Burton. 2014. Wastewater Engineering Treatment and Resource Recovery (5th ed.). Penn Plaza, NY: McGraw-Hill Education.

Meynard, Christine N., Antonio Lara, Mario Pino, Doris Soto, Laura Nahuelhual, Daisy Núñez, Cristian Echeverría, et al. 2007. "La integración de la ciencia, la economía y la sociedad: servicios ecosistémicos en la ecoregión de los bosques lluviosos valdivianos en el cono sur de Sudamérica." Gaceta Ecologica 29-38.

Mihelcic, James R., and Julie Beth Zimmerman. 2014. Environmental Engineering: Fundamentals, Sustainability, Design (2nd ed.). Hoboken, NJ: Wiley.

Mihelcic, James R., Lauren M. Fry, Elizabeth A. Myre, Linda D. Phillips, and Brian D. Barkdoll. 2009. Field Guide to Environmental Engineering for Development Workers. Reston, VA: American Society of Civil Engineers.

Moriarty, Patrick, Stef Smits, John Butterworth, and Richard Franceys. 2013. "Trends in Rural Water Supply: Towards a Service Delivery Approach." Water Alternatives 329-349.

Natural Resources Conservation Service. 2004. National Engineering Handbook. Beltsville, MD: United States Department of Agriculture.

Nelson, Melissa K., and Dan Shilling, . 2018. Traditional Ecological Knowledge Learning from Indigenous Practices for Environmental Sustainability. Cambridge: Cambridge University Press.

Paton, Steven. 2020. 2020 Meteorological and Oceanographic Summary for the Bocas del Toro Research Station. Bocas del Toro: Smithsonian Tropical Research Institute.

Riesch, Hauke, and Clive Potter. 2014. "Citizen science as seen by scientists: Methodological, epistemological and ethical dimensions." Public Understanding of Science 107-120.

Salimi, E. Taghvaye, A. Nohegar, A. Malekian, M. Hoseini, and A. Holisaz. 2017. "Estimating time of concentration in large watersheds." Paddy and Water Environment 123-132.

Sedeno-Diaz, Jacinto Elias, Bert Kohlmnan, and Eugenia Lopez-Lopez. 2012. "Benthic Macroinvertebrates as Indicators of Water Quality in Streams of Costa Rica: Using an Adaptation of the BMWP Score." Transylvanian Review.

Shinbrot, Xoco A., Lyssette Munoz-Villers, Alex Mayer, Melissa Lopez-Purata, Kelly Jones, Sergio Lopez-Ramirez, Carlos Alcocer-Lezama, Miriam Ramos-Excobedo, and Robert Manson. 2020. "Quiahua, the First Citizen Science Rainfall Monitoring Network in Mexico: Filling Critical Gaps in Rainfall Data for 
Evaluating a Payment for Hydrologic Sevices Program." Citizen Science: Theory and Practice 1-15.

Smithsonian Tropical Research Institute. 2021. BioGeoDB. Accessed January 2021. https://biogeodb.stri.si.edu/physical_monitoring/research/bocas.

Sowah, R., H. Zhang, D. Radcliffe, E. Bauske, and M.Y. Habteselassie. 2014.

"Evaluating the influence of septic systems and watershed characteristics on stream faecal pollution in suburban watersheds in Georgia, USA." Journal of Applied Microbiology 1500-1512.

Springer, Monika. 2009. "Aquatic insect diversity of Costa Rica: state of knowledge." Revista de Biologia Tropical 273-295.

Stedinger, Jery R., Richard M. Vogel, and Efi Foufoula-Georgiou. 1993. "Chapter 18: Frequency Analysis of Extreme Events." In Handbook of Hydrology, by D. R. Maidment. New York: McGraw-Hill.

Stein, Heide, Monika Springer, and Bert Kohlmann. 2008. "Comparison of two sampling methods for biomonitoring using aquatic macroinvertebrates in the Dos Novillos River, Costa Rica." Ecological Engineering 267-275.

USEPA. 2020. "An Overview of Renewable Natural Gas from Biogas."

-. 2000. Constructed Wetlands Treatment of Municipal Wastewaters. Cincinnati, Ohio: Office of Research and Development.

—. 2010. NPDES Permit Writers' Manual. Washington, DC: Water Permits Division, Office of Wastewater Management.

USEPA. 2002. "Onsite Wastewater Treatment Systems Manual."

Water Programs, Sacramento State. 2019. Operation of Wastewater Treatment Plants. New York, New York: Pearson Education.

Wurbs, Ralph A., and Wesley P. James. 2001. Water Resources Engineering. Upper Saddle River, NJ: Prentice Hall.

Young, C. Bryan, and Bruce M. McEnroe. 2003. "Sampling Adjustment Factors for Rainfall Recorded at Fixed Time Intervals." Journal of Hydrologic Engineering 294-296. 


\section{Appendix A. Copyright Documentation}

Maps by Google Maps. Obtained from earth.google.com/web/ unlicensed permission under fair use as described in Section 107 of the US Copyright Act and Google Maps Terms of Service. Accessed 2017. 


\section{Appendix B. Household wastewater data}

The following data were collected between September and November of 2018 as part of my Peace Corps service. During the first three months of service, Peace Corps Volunteers (PCV) conduct a Participatory Analysis for Community Action (PACA). This is a process of gathering information with and about the PCV's community of service in order to assist the development of goals and actions. The data below were part of the PACA. The data are from nearly every household in the San Francisco/Loma Brava neighborhood of Valle Risco and account for 500 of the approximately 2,500 inhabitants. In this table "septic" is the general term used to refer to any flush toilet system. "NO" indicates a lack of a permanent built wastewater system, and the household thus either uses a neighboring system, a community system, or open defecation.

\begin{tabular}{|c|c|}
\hline Number of people in household & Wastewater \\
\hline 8 & NO \\
\hline 7 & NO \\
\hline 43 & Septic \\
\hline 12 & Septic \\
\hline 8 & Septic \\
\hline 8 & NO \\
\hline 9 & NO \\
\hline 12 & Septic \\
\hline 7 & NO \\
\hline 5 & NO \\
\hline 3 & NO \\
\hline 1 & Septic \\
\hline 5 & NO \\
\hline 6 & Septic \\
\hline 8 & Septic \\
\hline 8 & Septic \\
\hline 14 & Compost \\
\hline 14 & Compost \\
\hline 13 & Compost \\
\hline 6 & Septic \\
\hline 2 & Septic \\
\hline 2 & NO \\
\hline 1 & Septic \\
\hline 7 & NO \\
\hline 9 & Septic \\
\hline 15 & NO \\
\hline 3 & Septic \\
\hline 11 & Pit Latrine \\
\hline
\end{tabular}




\begin{tabular}{|cc|}
10 & Septic \\
8 & Septic \\
9 & Septic \\
4 & Pit Latrine \\
8 & Pit Latrine \\
21 & Pit Latrine \\
3 & Compost \\
4 & Septic \\
4 & Septic \\
2 & Compost \\
1 & Pit Latrine \\
11 & Pit Latrine \\
7 & Pit Latrine \\
9 & Pit Latrine \\
5 & Pit Latrine \\
5 & NO \\
9 & NO \\
5 & Pit Latrine \\
2 & Pit Latrine \\
3 & Pit Latrine \\
8 & Pit Latrine \\
12 & Pit Latrine \\
7 & Pit Latrine \\
10 & Septic \\
13 & Septic \\
8 & Compost \\
2 & Pit Latrine \\
10 & Pit Latrine \\
5 & Septic \\
6 & Septic \\
9 & Septic \\
5 & \\
\hline & \\
\hline &
\end{tabular}




\section{Appendix C. Rainfall statistical analysis}

Rainfall data were acquired from the STRI biogeo database and annual maximum values for durations of 1 to 24 hours were determined (Table 8) (Smithsonian Tropical Research Institute 2021).

Table 8. Maximum rainfall events for 2002-2020. Data from STRI 2021.

\begin{tabular}{|c|cccccc|}
\hline \multicolumn{7}{|c|}{ Yearly maximum rainfall (in/hr) } \\
\hline Year & 1 hour & 2 hour & 3 hour & 6 hour & 12 hour & 24 hour \\
\hline 2002 & 3.20 & 5.00 & 5.90 & 8.70 & 9.10 & 10.30 \\
2003 & 1.80 & 2.60 & 3.00 & 4.60 & 6.10 & 6.80 \\
2004 & 1.80 & 2.40 & 2.90 & 4.30 & 4.80 & 6.90 \\
2005 & 1.30 & 1.60 & 2.00 & 3.00 & 4.80 & 7.90 \\
2006 & 0.96 & 1.50 & 1.83 & 2.13 & 2.77 & 3.52 \\
2007 & 1.05 & 1.82 & 2.28 & 2.72 & 2.96 & 3.01 \\
2008 & 0.75 & 1.29 & 1.75 & 2.33 & 3.99 & 5.16 \\
2009 & 0.96 & 1.60 & 1.81 & 2.42 & 3.19 & 5.43 \\
2010 & 1.08 & 1.70 & 2.20 & 2.83 & 3.35 & 3.38 \\
2011 & 1.14 & 1.91 & 2.43 & 2.83 & 3.22 & 4.87 \\
2012 & 0.90 & 1.47 & 1.70 & 1.92 & 2.52 & 4.52 \\
2013 & 1.00 & 1.72 & 2.42 & 3.01 & 3.74 & 4.32 \\
2014 & 0.98 & 1.72 & 2.13 & 2.80 & 2.87 & 3.80 \\
2015 & 0.93 & 1.67 & 2.00 & 3.45 & 5.13 & 5.99 \\
2016 & 1.07 & 1.74 & 2.18 & 2.86 & 2.99 & 3.10 \\
2017 & 1.02 & 1.68 & 2.29 & 3.40 & 3.82 & 4.08 \\
2018 & 1.08 & 1.55 & 1.96 & 2.24 & 3.14 & 4.14 \\
2019 & 1.13 & 2.02 & 2.67 & 3.75 & 6.54 & 9.39 \\
2020 & 1.40 & 2.22 & 3.01 & 4.17 & 4.56 & 4.84 \\
\hline
\end{tabular}

An initial analysis used the Weibull plotting-position formula following Dingman (2002), where the yearly maximum values were sorted largest to smallest for each duration storm and then ranked. Exceedance probabilities were estimated as $E P=i /(N+1)$ where $i$ is the rank of the data and $N$ is the number of values (Table 9 ). Yearly occurrences were given as the inverse of the exceedance probabilities (Figure 20). It is noted that these values are not ideal considering the 10 -year line passes very close to the 5-year line. This is likely due to the short period of data collection (19 years). 
Table 9. Sorted and ranked yearly maximum rainfall for use in the Weibull method.

\begin{tabular}{|cc|cccccc|c|}
\hline \multicolumn{8}{|c|}{ Max yearly rainfall (in/hr) (Weibull) } \\
\hline Rank & EP & 1 & 2 & 3 & 6 & 12 & 24 & YEAR \\
\hline 1 & 0.05 & 81.28 & 63.50 & 49.95 & 36.83 & 19.26 & 10.90 & 20.00 \\
2 & 0.1 & 45.72 & 33.02 & 25.49 & 19.47 & 13.84 & 9.94 & 10.00 \\
3 & 0.15 & 45.72 & 30.48 & 25.40 & 18.20 & 12.91 & 8.36 & 6.67 \\
4 & 0.2 & 35.56 & 28.20 & 24.55 & 17.65 & 10.86 & 7.30 & 5.00 \\
5 & 0.25 & 33.02 & 25.66 & 22.61 & 15.88 & 10.16 & 7.20 & 4.00 \\
6 & 0.3 & 28.96 & 24.26 & 20.58 & 14.61 & 10.16 & 6.34 & 3.33 \\
7 & 0.35 & 28.70 & 23.12 & 20.49 & 14.39 & 9.65 & 5.75 & 2.86 \\
8 & 0.4 & 27.43 & 22.10 & 19.39 & 12.74 & 8.45 & 5.46 & 2.50 \\
9 & 0.45 & 27.43 & 21.85 & 19.30 & 12.70 & 8.08 & 5.15 & 2.22 \\
10 & 0.5 & 27.18 & 21.85 & 18.63 & 12.11 & 7.92 & 5.12 & 2.00 \\
11 & 0.55 & 26.67 & 21.59 & 18.46 & 11.98 & 7.09 & 4.78 & 1.82 \\
12 & 0.6 & 25.91 & 21.34 & 18.03 & 11.98 & 6.82 & 4.57 & 1.67 \\
13 & 0.65 & 25.40 & 21.21 & 16.93 & 11.85 & 6.75 & 4.38 & 1.54 \\
14 & 0.7 & 24.89 & 20.32 & 16.93 & 11.52 & 6.65 & 4.32 & 1.43 \\
15 & 0.75 & 24.38 & 20.32 & 16.59 & 10.24 & 6.33 & 4.02 & 1.33 \\
16 & 0.8 & 24.38 & 19.69 & 15.50 & 9.86 & 6.27 & 3.73 & 1.25 \\
17 & 0.85 & 23.62 & 19.05 & 15.32 & 9.48 & 6.07 & 3.58 & 1.18 \\
18 & 0.9 & 22.86 & 18.67 & 14.82 & 9.02 & 5.86 & 3.28 & 1.11 \\
19 & 0.95 & 19.05 & 16.39 & 14.40 & 8.13 & 5.33 & 3.19 & 1.05 \\
\hline
\end{tabular}




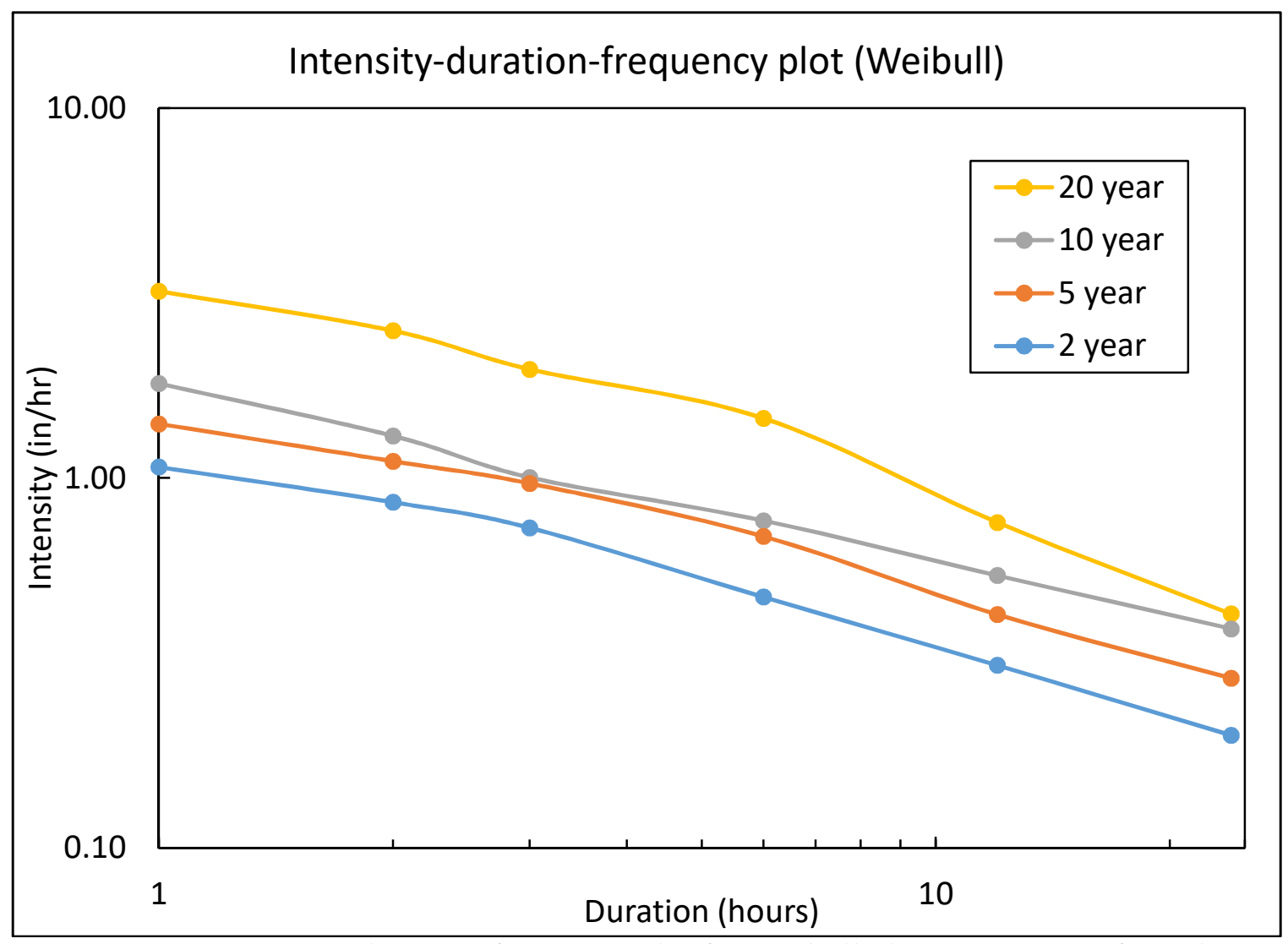

Figure 20. Intensity-duration-frequency plot for Weibull plotting-position formula.

To account for the short time period, the data were modeled using the Generalized Extreme Value distribution (GEV). This method is frequently used to estimate the frequency of extreme events from short-period data in hydrological analysis (Hosking, Wallis and Wood 1984). Probability weighted linear moments (L-moments) were used to calculate parameters used in constructing the probability distribution (Stedinger, Vogel and Foufoula-Georgiou 1993). First, PWM estimators are calculated by

$$
\begin{gathered}
b_{0}=\bar{X} \\
b_{1}=\sum_{j=1}^{n-1} \frac{(n-j) X_{j}}{n(n-1)} \\
b_{2}=\sum_{j=1}^{n-2} \frac{(n-j)(n-j-1) X_{j}}{n(n-1)(n-2)}
\end{gathered}
$$




$$
b_{1}=\sum_{j=1}^{n-3} \frac{(n-j)(n-j-1)(n-j-2) X_{j}}{n(n-1)(n-2)(n-3)}
$$

where $X_{j}$ are the maximum values to be modeled, and $n$ is the number of values. These are used to calculate the L-moments,

$$
\begin{gathered}
\lambda_{1}=\beta_{0} \\
\lambda_{2}=2 \beta_{1}-\beta_{0} \\
\lambda_{3}=6 \beta_{2}-6 \beta_{1}+\beta_{0} \\
\lambda_{4}=20 \beta_{3}-30 \beta_{2}+12 \beta_{1}-\beta_{0} .
\end{gathered}
$$

where estimators $b_{i}$ are substituted for unknown $\beta_{0}$. These values are then used to calculate parameters,

$$
\begin{gathered}
\kappa=7.8590 c+2.9554 c^{2} \\
\alpha=\frac{\kappa \lambda_{2}}{\Gamma(1+\kappa)\left(1-2^{-\kappa}\right)} \\
\xi=\lambda_{1}+\frac{\alpha[\Gamma(1+\kappa)-1]}{\kappa}
\end{gathered}
$$

where $\Gamma(x)$ is the gamma function and

$$
c=\frac{2 \lambda_{2}}{\lambda_{3}+3 \lambda_{2}}-\frac{\ln (2)}{\ln (3)}
$$

The GEV distribution is hence given by

$$
x_{p}=\xi+\frac{\alpha}{\kappa}\left\{1-[-\ln (p)]^{\kappa}\right.
$$

where $p$ is the probability of interest. This was adapted into an Excel spreadsheet following (Ilaboya and Otuaro 2019) giving the sorted maxima in Table 10, resulting in the corresponding IDF curves in Figure 21. 
Table 10. GEV distribution values.

\begin{tabular}{|cc|cccccc|c|}
\hline \multicolumn{10}{|c|}{ Max yearly rainfall (in/hr) (GEV) } \\
\hline Rank & EP & 1 & 2 & 3 & 6 & 12 & 24 & YEAR \\
\hline 1 & 0.05 & 2.10 & 1.57 & 1.32 & 0.99 & 0.62 & 0.40 & 20.00 \\
2 & 0.1 & 1.66 & 1.27 & 1.09 & 0.80 & 0.51 & 0.33 & 10.00 \\
3 & 0.15 & 1.47 & 1.13 & 0.98 & 0.71 & 0.45 & 0.30 & 6.67 \\
4 & 0.2 & 1.35 & 1.05 & 0.91 & 0.65 & 0.42 & 0.28 & 5.00 \\
5 & 0.25 & 1.27 & 1.00 & 0.86 & 0.61 & 0.39 & 0.26 & 4.00 \\
6 & 0.3 & 1.21 & 0.95 & 0.82 & 0.57 & 0.37 & 0.24 & 3.33 \\
7 & 0.35 & 1.16 & 0.92 & 0.79 & 0.54 & 0.35 & 0.23 & 2.86 \\
8 & 0.4 & 1.12 & 0.89 & 0.76 & 0.52 & 0.33 & 0.22 & 2.50 \\
9 & 0.45 & 1.08 & 0.87 & 0.74 & 0.50 & 0.32 & 0.21 & 2.22 \\
10 & 0.5 & 1.05 & 0.85 & 0.72 & 0.48 & 0.31 & 0.20 & 2.00 \\
11 & 0.55 & 1.03 & 0.83 & 0.70 & 0.47 & 0.30 & 0.19 & 1.82 \\
12 & 0.6 & 1.00 & 0.82 & 0.69 & 0.45 & 0.29 & 0.18 & 1.67 \\
13 & 0.65 & 0.98 & 0.80 & 0.67 & 0.44 & 0.28 & 0.18 & 1.54 \\
14 & 0.7 & 0.96 & 0.79 & 0.66 & 0.42 & 0.27 & 0.17 & 1.43 \\
15 & 0.75 & 0.94 & 0.77 & 0.64 & 0.41 & 0.26 & 0.16 & 1.33 \\
16 & 0.8 & 0.92 & 0.76 & 0.63 & 0.39 & 0.25 & 0.15 & 1.25 \\
17 & 0.85 & 0.90 & 0.75 & 0.61 & 0.38 & 0.24 & 0.14 & 1.18 \\
18 & 0.9 & 0.88 & 0.73 & 0.60 & 0.36 & 0.22 & 0.13 & 1.11 \\
19 & 0.95 & 0.85 & 0.71 & 0.58 & 0.34 & 0.21 & 0.12 & 1.05 \\
\hline
\end{tabular}




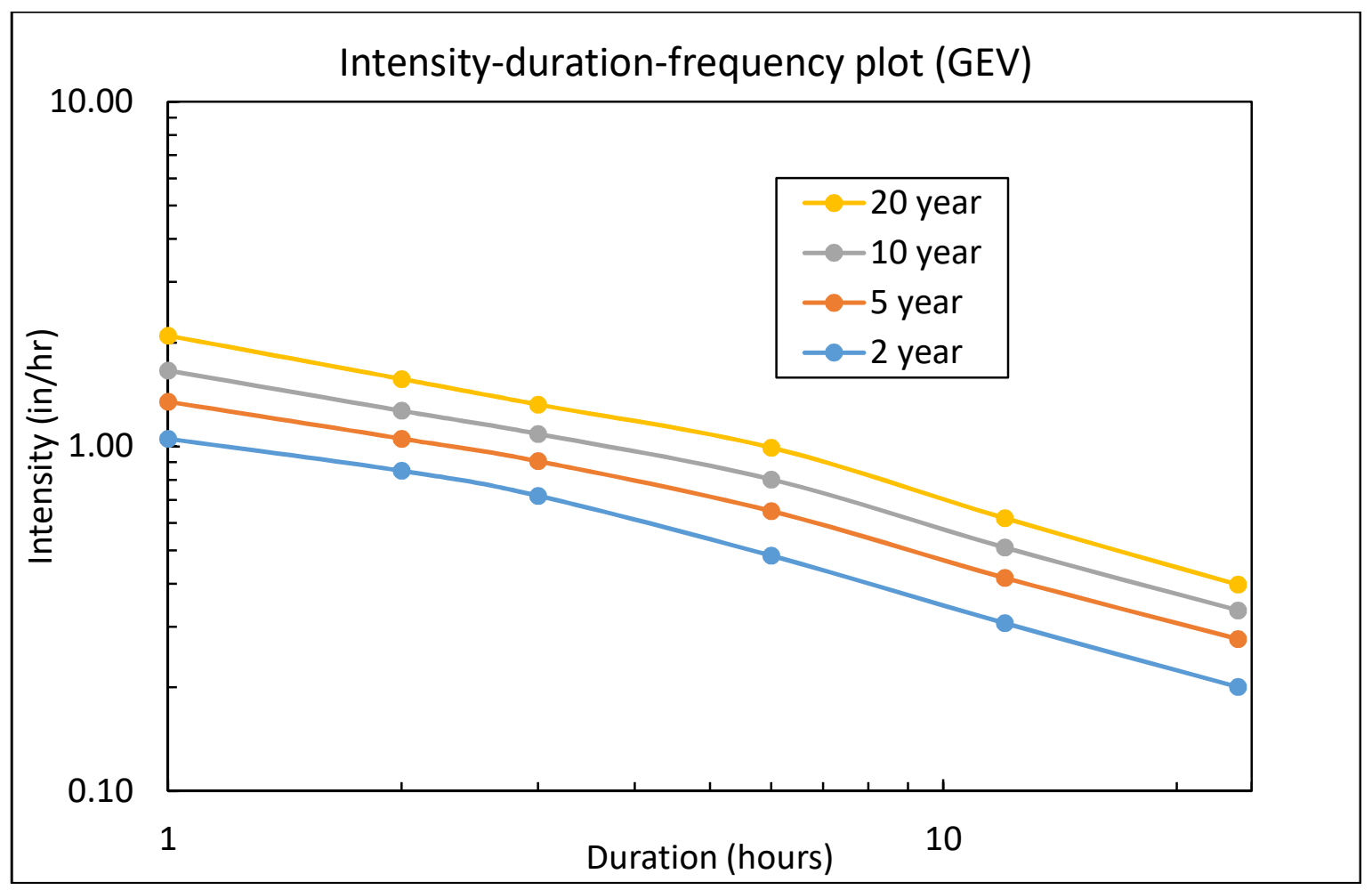

Figure 21. Intensity-duration-frequency plot for GEV distribution.

The sampling frequency for these data was one hour meaning that estimates of shorter duration events would have greater inaccuracy. This was corrected by multiplying by an adjustment factor following Young and McEnroe (2003; Table 11, 12, Figure 22). The sampling ratio refers to the ratio of the event duration to the sampling interval

$$
n=\frac{D}{\Delta t}
$$

where $\mathrm{D}$ is the event duration, $\Delta \mathrm{t}$ is the sampling duration, and $\mathrm{n}$ is the sampling ratio (Table 11).

Table 11. Adjustment factors for given sampling ratios. Values from Young and McEnroe

\begin{tabular}{|c|cccccc|}
\hline Sampling ratio & 1 & 2 & 3 & 6 & 12 & 24 \\
Adjustment factor & 1.13 & 1.05 & 1.03 & 1.01 & 1 & 1 \\
\hline
\end{tabular}


Table 12. Adjusted GEV values for maximum yearly rainfall intensity.

\begin{tabular}{|cc|cccccc|c|}
\hline \multicolumn{7}{|c|}{ Max yearly rainfall (in/hr) (GEV adjusted) } \\
\hline Rank & EP & 1 & 2 & 3 & 6 & 12 & 24 & YEAR \\
\hline 1 & 0.05 & 2.37 & 1.65 & 1.36 & 1.00 & 0.62 & 0.40 & 20.00 \\
2 & 0.1 & 1.88 & 1.33 & 1.12 & 0.81 & 0.51 & 0.33 & 10.00 \\
3 & 0.15 & 1.66 & 1.19 & 1.01 & 0.72 & 0.45 & 0.30 & 6.67 \\
4 & 0.2 & 1.52 & 1.11 & 0.93 & 0.66 & 0.42 & 0.28 & 5.00 \\
5 & 0.25 & 1.43 & 1.05 & 0.88 & 0.61 & 0.39 & 0.26 & 4.00 \\
6 & 0.3 & 1.36 & 1.00 & 0.84 & 0.58 & 0.37 & 0.24 & 3.33 \\
7 & 0.35 & 1.31 & 0.97 & 0.81 & 0.55 & 0.35 & 0.23 & 2.86 \\
8 & 0.4 & 1.26 & 0.94 & 0.78 & 0.53 & 0.33 & 0.22 & 2.50 \\
9 & 0.45 & 1.22 & 0.91 & 0.76 & 0.51 & 0.32 & 0.21 & 2.22 \\
10 & 0.5 & 1.19 & 0.89 & 0.74 & 0.49 & 0.31 & 0.20 & 2.00 \\
11 & 0.55 & 1.16 & 0.87 & 0.72 & 0.47 & 0.30 & 0.19 & 1.82 \\
12 & 0.6 & 1.13 & 0.86 & 0.71 & 0.45 & 0.29 & 0.18 & 1.67 \\
13 & 0.65 & 1.11 & 0.84 & 0.69 & 0.44 & 0.28 & 0.18 & 1.54 \\
14 & 0.7 & 1.08 & 0.83 & 0.68 & 0.43 & 0.27 & 0.17 & 1.43 \\
15 & 0.75 & 1.06 & 0.81 & 0.66 & 0.41 & 0.26 & 0.16 & 1.33 \\
16 & 0.8 & 1.04 & 0.80 & 0.65 & 0.40 & 0.25 & 0.15 & 1.25 \\
17 & 0.85 & 1.02 & 0.78 & 0.63 & 0.38 & 0.24 & 0.14 & 1.18 \\
18 & 0.9 & 0.99 & 0.77 & 0.61 & 0.37 & 0.22 & 0.13 & 1.11 \\
19 & 0.95 & 0.96 & 0.75 & 0.59 & 0.35 & 0.21 & 0.12 & 1.05 \\
\hline
\end{tabular}




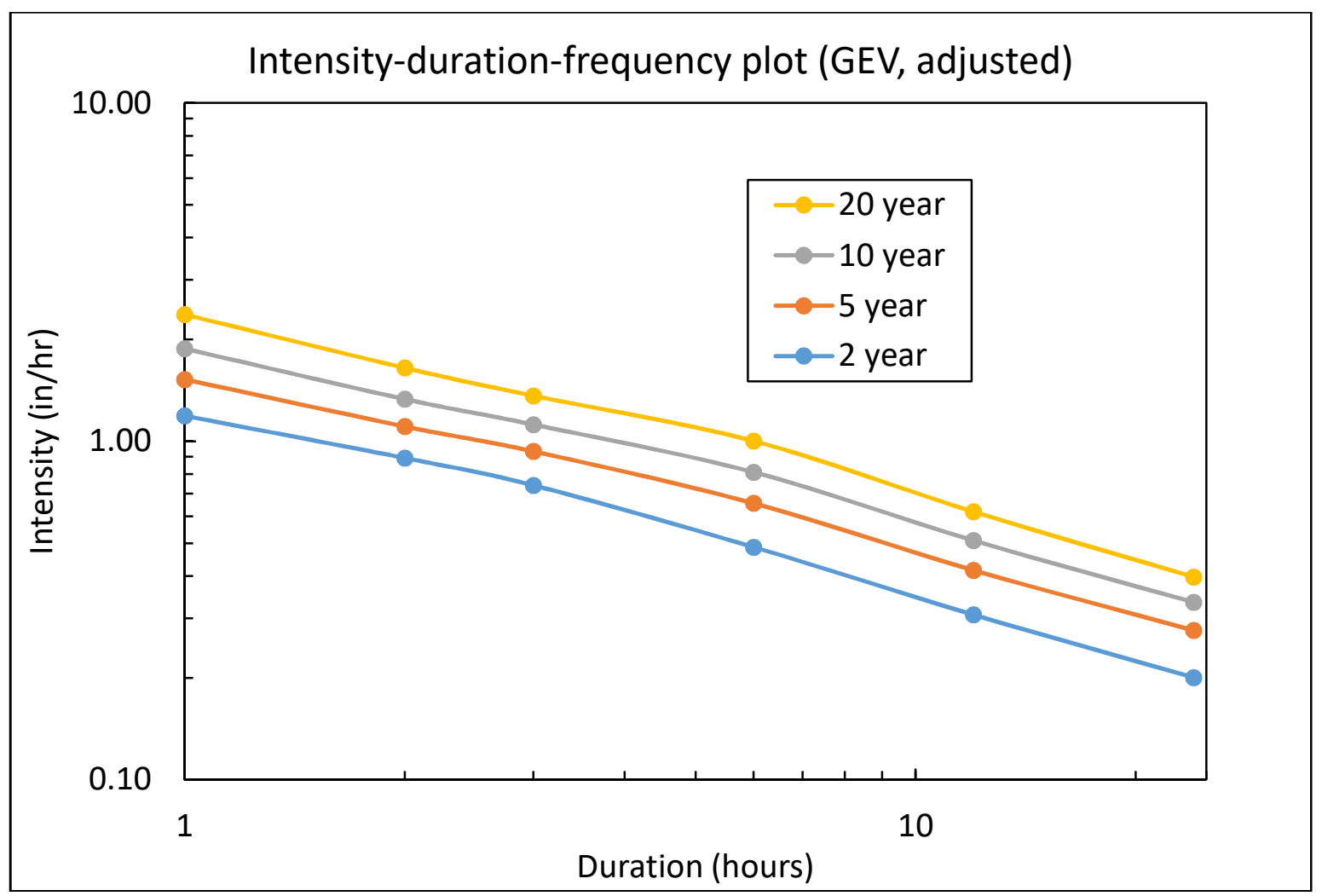

Figure 22. IDF curves for adjusted GEV values. 